\title{
Sox17 expression confers self-renewal potential and fetal stem cell characteristics upon adult hematopoietic progenitors
}

\author{
Shenghui He, ${ }^{1}$ Injune Kim, ${ }^{2}$ Megan S. Lim, ${ }^{3}$ and Sean J. Morrison ${ }^{1,4}$ \\ ${ }^{1}$ Howard Hughes Medical Institute, Life Sciences Institute, Department of Internal Medicine, Center for Stem Cell Biology, \\ University of Michigan, Ann Arbor, Michigan 48109, USA; ${ }^{2}$ Graduate School of Medical Science and Engineering, Korea \\ Advanced Institute of Science and Technology, Daejeon, 305-701, Republic of Korea; ${ }^{3}$ Department of Pathology, University of \\ Michigan, Ann Arbor, Michigan 48109, USA
}

\begin{abstract}
A key question concerns the mechanisms that determine temporal identity in stem cells. Fetal hematopoietic stem cells (HSCs) differ from adult HSCs in terms of gene expression profile, surface marker expression, differentiation, and self-renewal capacity. We previously showed that the transcription factor SOX17 is expressed by fetal, but not adult, HSCs and is required for the maintenance of fetal and neonatal, but not adult, HSCs. In the current study, we show that ectopic expression of Sox 17 in adult HSCs and transiently reconstituting multipotent progenitors was sufficient to confer increased self-renewal potential and the expression of fetal HSC genes, including fetal HSC surface markers. Sox17 expression enabled transiently reconstituting adult progenitors to give long-term multilineage reconstitution that resembled fetal hematopoiesis, including increased erythropoiesis, increased myelopoiesis, and decreased lymphopoiesis. Long-term ectopic expression of Sox17 eventually led to leukemogenesis. These data demonstrate that SOX17 is sufficient to confer fetal HSC characteristics to adult hematopoietic progenitors and is therefore a key determinant of fetal HSC identity.
\end{abstract}

[Keywords: Sox17; fetal; hematopoietic stem cell; self-renewal]

Supplemental material is available for this article.

Received March 20, 2011; revised version accepted June 22, 2011.

Mammalian hematopoiesis undergoes significant developmental changes. Two distinct waves of blood cell production occur in mouse embryos (Mikkola and Orkin 2006; Orkin and Zon 2008). "Primitive" hematopoiesis first occurs in the yolk sac at embryonic day 7 (E7) and is characterized by myelopoiesis and the production of primitive erythrocytes, which are nucleated and express embryonic hemoglobins. Primitive hematopoiesis is transient and does not involve transplantable hematopoietic stem cells (HSCs) (Cumano et al. 1996, 2001). Primitive hematopoiesis is replaced by "definitive" hematopoiesis, in which transplantable HSCs arise around E8.5 intraembryonically (Medvinsky and Dzierzak 1996; Sanchez et al. 1996; Cumano et al. 2001), as well as potentially within the yolk sac (Weissman et al. 1978; Yoder et al. 1997; Samokhvalov et al. 2007) and placenta (Gekas et al. 2005; Lee et al. 2010). These HSCs migrate into the fetal

${ }^{4}$ Corresponding author.

E-mail seanjm@umich.edu.

Article is online at http://www.genesdev.org/cgi/doi/10.1101/gad.2052911. liver where they establish definitive hematopoiesis that endures throughout the rest of gestation.

Fetal liver hematopoiesis differs from both primitive yolk sac hematopoiesis and from adult bone marrow hematopoiesis. In contrast to primitive hematopoiesis, definitive hematopoiesis from fetal liver HSCs involves the production of definitive erythrocytes that, like adult erythrocytes, are enucleated and express adult hemoglobins. However, in contrast to adult hematopoiesis, fetal liver hematopoiesis involves mainly erythropoiesis and myelopoiesis, with limited lymphopoiesis. Fetal liver HSCs are also phenotypically and functionally different from adult HSCs, even though both give rise to definitive hematopoiesis. Fetal and adult HSCs differ in terms of gene expression profile (Phillips et al. 2000; Ivanova et al. 2002; Kiel et al. 2005a), surface marker expression (Jordan and Lemischka 1990; Morrison et al. 1995; Kim et al. 2005), developmental potential (Ikuta et al. 1990; Kantor et al. 1992; Bowie et al. 2007), and self-renewal capacity (Morrison et al. 1995; Harrison et al. 1997; Bowie et al. 2007).

Key transcriptional regulators also differ between fetal and adult HSCs. Fetal and neonatal HSCs require SOX17 
He et al.

for their maintenance, but adult HSCs do not (Kim et al. 2007). In contrast, adult HSCs require GFI-1 (Hock et al. 2004a), ETV6 (Hock et al. 2004b), and BMI1 (Park et al. 2003), but fetal HSCs do not. While it is clear that fetal and adult HSCs depend on different transcriptional regulators, the mechanisms that actually determine the temporal identity of HSCs remain unknown.

SOX17 is a member of subgroup F of the Sry-related high-mobility group box (Sox) transcription factors and has been considered a marker of endodermal identity (Yasunaga et al. 2005). It is required for the formation and maintenance of definitive endoderm during early development (Hudson et al. 1997; Kanai-Azuma et al. 2002; Niakan et al. 2010) and is required, along with Sox18, for the formation of vascular endothelium (Matsui et al. 2006). Within the hematopoietic system, Sox17 expression is highly restricted to fetal and neonatal, but not adult, HSCs (Kim et al. 2007). Germline deficiency for Sox17 leads to severe defects in definitive hematopoiesis, including a complete absence of definitive HSCs, while postnatal deletion of Sox17 leads to the rapid loss of neonatal but not adult HSCs (Kim et al. 2007). Nonetheless, it is unclear whether SOX17 specifies fetal HSC properties or whether it only promotes the maintenance of these cells.

To test whether Sox17 is sufficient to confer fetal HSC properties, we ectopically expressed Sox17 in adult mouse hematopoietic cells by retroviral infection and followed their fate after transplantation into irradiated recipient mice. Sox17 expression was sufficient to increase the selfrenewal potential of transiently reconstituting multipotent progenitors (MPPs) and to confer on these cells the potential for long-term multilineage reconstitution. Sox17expressing adult progenitors also expressed fetal HSC surface markers and exhibited increased expression of fetal HSC genes. Sox17-expressing adult progenitors also gave rise to hematopoiesis in adult bone marrow that resembled fetal liver hematopoiesis, with increased erythropoiesis, increased myelopoiesis, and reduced lymphopoiesis. Sox17 is sufficient to confer fetal HSC properties and is therefore a key determinant of fetal HSC identity.

\section{Results}

Sox17 expression in HSCs declines with developmental time and lineage restriction

To better understand the function of SOX17 in fetal hematopoiesis, we examined the expression of Sox17 in detail at E13.5, at birth (P0), and at 2 wk of age using Sox17-GFP knock-in mice (Kim et al. 2007). As we reported previously (Kim et al. 2007), Sox17-GFP expression was highly restricted to early hematopoietic progenitors in the fetal liver. Only $\sim 1 \%$ of E13.5 fetal liver cells expressed Sox17 (Fig. 1A), and many of these cells

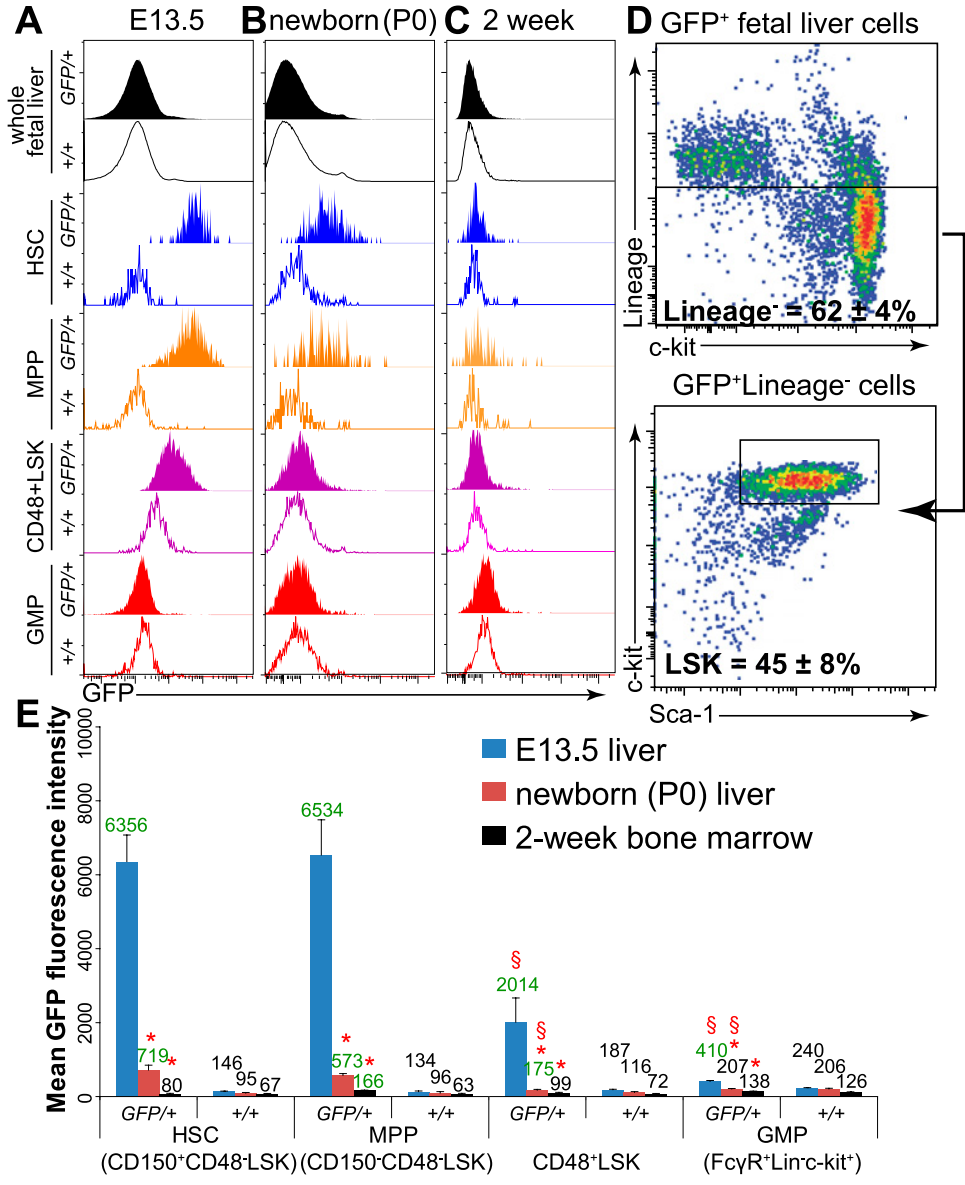

Figure 1. Sox17 expression is restricted to immature hematopoietic stem/progenitor cells from fetal and neonatal mice. Representative histograms showing the distribution of Sox17 expression based on GFP fluorescence in Sox $17^{G F P /+}$ mice at E13.5 $(A)$, P0 $(B)$, and 2 wk of age $(C)$ in HSCs, MPPs, CD $48^{+}$LSK cells, and GMPs. Histograms of the same cell populations from Sox $17^{+/+}$mice are shown as negative controls. $(A)$ At E13.5, GFP expression was observed in HSCs, MPPs, and CD $488^{+}$LSK cells, but not in GMPs or in most other fetal liver cells. $(B)$ At P0, lower levels of GFP could still be observed in HSCs and MPPs, but not in CD48 ${ }^{+}$LSK cells, GMPs, or most other newborn liver cells. (C) GFP expression was not detected in any hematopoietic cells from 2-wk-old Sox $17^{G F P /+}$ mice. (D) Many $\mathrm{GFP}^{+}$fetal liver cells from Sox $17^{\mathrm{GFP} /+}$ mice at E13.5 were LSK hematopoietic stem/progenitor cells. $(E)$ Mean GFP fluorescence intensity for each sorted cell population. $\left.{ }^{*}\right)$ Significantly different $(P<0.05)$ from the same cell population at E13.5; $(\S)$ significantly different $(P<0.05)$ from HSCs at the same developmental stage; (green numbers) significant difference from Sox $17^{+/+}$control cells at the same developmental stage. Data are from three to four independent experiments. All error bars indicate SD. 
were Lineage ${ }^{-}$Sca- $1^{+}$c-kit ${ }^{+}$(LSK) hematopoietic stem/ progenitor cells (Fig. 1D). At E13.5, virtually all CD $150^{+}$CD48 ${ }^{-}$LSK HSCs (Kiel et al. 2005b; Kim et al. 2006) and CD150 ${ }^{-}$CD $48^{-}$LSK MPPs (Kiel et al. 2008) expressed Sox17 (Fig. 1A). In contrast, Sox17 expression was lower and more difficult to distinguish from background in CD48 ${ }^{+}$LSK cells, which contain heterogeneous restricted progenitors (Fig. 1A). Fc $\gamma \mathrm{R}^{+}$Lineage $^{-}$Sca- $1^{-}$c-kit ${ }^{+}$ granulocyte/macrophage progenitors (GMPs) (Akashi et al. 2000) did not detectably express Sox17 (Fig. 1A).

In the newborn (P0) liver, a major site of hematopoiesis, Sox17 expression remained highly restricted to hematopoietic stem/progenitor cells (Fig. 1B). Less than $1 \%$ of all newborn liver cells expressed Sox17. Most or all newborn HSCs and MPPs expressed Sox17, but at levels lower than in fetal HSCs and MPPs (Fig. 1, cf. A and B). Sox17 expression was not detected in newborn CD $48^{+}$LSK cells or GMPs (Fig. 1B). Sox17 expression further declined postnatally, such that by 2 wk of age we were unable to detect Sox17 expression in any of these hematopoietic populations, including HSCs (Fig. 1C). Sox17 expression in HSCs, MPPs, and CD $48^{+}$LSK cells declined markedly during late fetal development and could no longer be detected 2 wk after birth (Fig. 1E).

Sox17 expression increases the reconstituting potential of adult hematopoietic cells

To test whether Sox17 expression in adult hematopoietic cells is sufficient to confer fetal characteristics, we ectopically expressed Sox17 in adult hematopoietic cells and followed their fate after transplantation into irradiated mice. We constructed two Sox17-expressing retroviral vectors by inserting full-length or C-terminal histagged Sox17 cDNA into the murine stem cell virus (MSCV)-based pMIG (MSCV-GFP) vector (Van Parijs et al. 1999) upstream of an internal ribosomal entry site (IRES), followed by EGFP (Supplemental Fig. 1A). Ectopic SOX17 expression was confirmed by Western blotting of SOX17 protein in Sox17 retrovirus-infected 3T3 cells and in splenocytes isolated from primary recipient mice reconstituted with Sox17 retrovirus-infected cells (Supplemental Fig. 1B). Retroviral overexpression generated SOX17 protein in adult LSK cells at $\sim 15$ times the level observed in E12 fetal liver LSK progenitors (Supplemental Fig. 1D).

To test the function of retrovirally expressed Sox17, we first assessed its effect on the reconstituting potential of adult bone marrow cells. One-million donor (CD45.1) bone marrow cells from 5-fluoruracil-treated 8-wk-old mice were infected during a brief (36-h) culture period (Pear et al. 1998) with control (MSCV-GFP) or Sox17 (MSCV-Sox17 and MSCV-Sox17his) retrovirus and transplanted into lethally irradiated CD45.2 recipients along with 200,000 recipient cells for radioprotection. The contribution of $\mathrm{GFP}^{+}$donor cells to peripheral blood chimerism was monitored for $16 \mathrm{wk}$ after transplantation (Fig. 2A-F). Peripheral blood myeloid cells, lymphoid cells, erythrocytes, and platelets derived from virus-infected donor cells were quantified by flow cytometry based on
EGFP expression (Supplemental Fig. 2). Compared with control virus-infected cells, bone marrow cells infected with either Sox17 virus gave significantly higher levels of peripheral blood myeloid $\left(\mathrm{Mac}^{-} \mathrm{1}^{+}\right.$or $\left.\mathrm{Gr}-\mathrm{1}^{+}\right)$(Fig. 2A,B), erythroid $\left(\right.$ Ter1 $\left.19^{+}\right)$(Fig. 2C), and platelet $\left(\mathrm{CD}^{+} 1^{+}\right)$(Fig. 2D) reconstitution. These data demonstrate that ectopic Sox17 expression in adult hematopoietic cells significantly increased long-term reconstitution by myeloid cells, erythrocytes, and platelets.

In contrast to the increased myeloerythroid reconstitution by Sox17-expressing cells, lymphoid reconstitution by Sox17-expressing cells often did not significantly differ from the control virus-infected cells (Fig. 2E,F). Bone marrow cells infected with MSCV-Sox17 gave significantly higher levels of long-term B-lineage reconstitution $\left(\mathrm{B}^{2} 20^{+}\right)$(Fig. 2E) than cells infected with the MSCV-GFP control vector, but B-lineage reconstitution by cells infected with MSCV-Sox17his did not differ from control cells. Sox17 expression did not significantly affect T-lineage reconstitution in peripheral blood (Fig. 2F). Thus, ectopic Sox17 expression in adult hematopoietic cells significantly increased reconstitution by myeloid cells, erythroid cells, and platelets, but did not necessarily increase reconstitution by lymphoid cells beyond the levels observed from control cells.

Overall, ectopic Sox17 expression increased long-term multilineage reconstitution by adult hematopoietic cells, as only five of 14 (36\%) recipients of control (MSCV-GFPinfected) cells exhibited long-term multilineage reconstitution but all nine $(100 \%)$ recipients of MSCV-Sox17infected cells and eight of nine (89\%) recipients of MSCVSox17his-infected cells were long-term multilineagereconstituted by myeloid, erythroid, $\mathrm{B}$, and $\mathrm{T}$ cells plus platelets (Fig. 1G). These results were reminiscent of reconstitution by fetal liver HSCs, which are present at a higher frequency than bone marrow HSCs and which give higher levels of reconstitution than similar numbers of bone marrow HSCs (Morrison et al. 1995).

\section{Sox17 expression alters adult hematopoiesis to resemble fetal hematopoiesis}

We examined hematopoiesis in recipients of Sox17expressing adult cells in detail to assess whether donor hematopoiesis in these mice resembled fetal hematopoiesis. Consistent with definitive hematopoiesis, Sox17expressing cells did not give rise to circulating nucleated erythrocytes or to embryonic hemoglobins, properties characteristic of primitive hematopoiesis (Fig. 2I; data not shown). Both MSCV-Sox17-infected cells and MSCVSox17his-infected cells gave significantly higher ratios of myeloid to lymphoid reconstitution as compared with MSCV-GFP-infected control cells (Fig. 2H). This was reminiscent of fetal hematopoiesis, which involves mainly myelopoiesis and erythropoiesis, in contrast to adult bone marrow hematopoiesis, which involves more lymphopoiesis. In E13.5 fetal liver, $91 \% \pm 1 \%$ of cells were Ter $119^{+}$ erythroid lineage cells, $2.0 \% \pm 0.1 \%$ were Mac- $1^{+}$myeloid lineage cells, $0.4 \% \pm 0.1 \%$ were $\mathrm{CD}^{2} 1^{+}$megakaryocyte lineage cells, and $<1 \%$ were lymphoid cells, in contrast to 
A
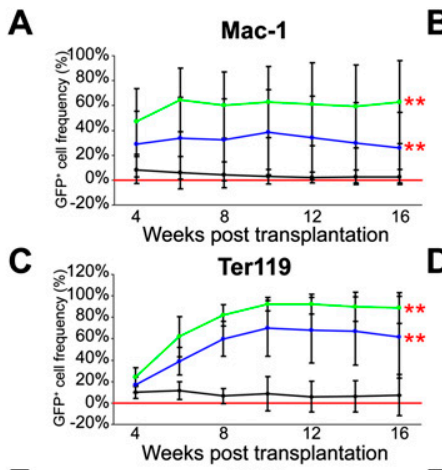

E

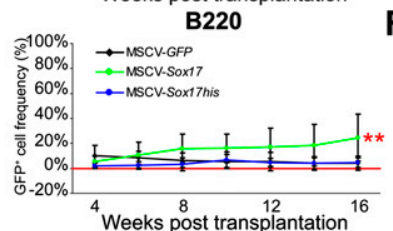

$\mathbf{F}$

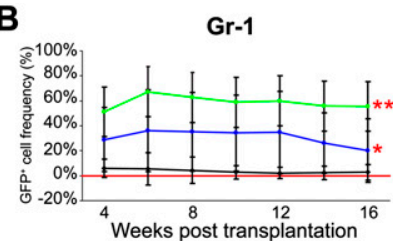

$\mathbf{D}_{\mathrm{s}^{120 \%}}$

Weeks post transplantation

CD41
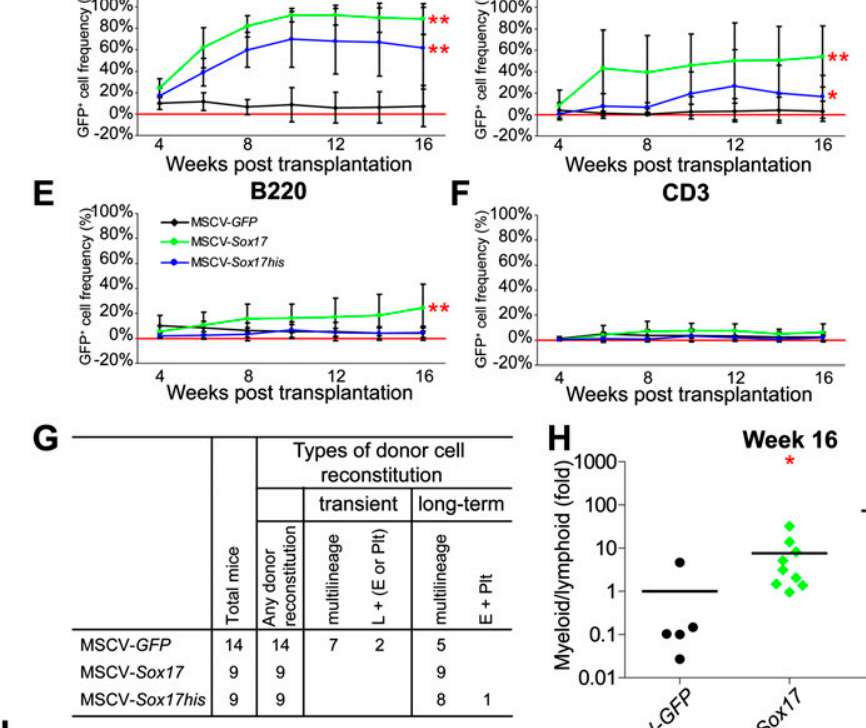

$\mathbf{I}$

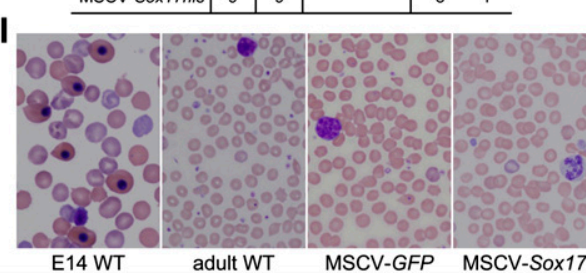

\section{H}

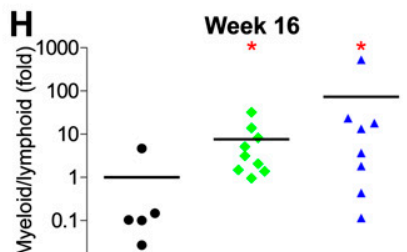

Figure 2. Ectopic Sox17 expression in adult bone marrow cells enhances their potential to give long-term multilineage reconstitution of irradiated mice. Onemillion donor (CD45.1) bone marrow cells infected with MSCV-GFP control virus, MSCV-Sox17, or MSCVSox17his virus were transplanted into 8-wk-old lethally irradiated CD45.2 recipients along with 200,000 CD45.2 bone marrow cells. $(A-F)$ At 16-wk after transplantation, Sox17-expressing bone marrow cells gave rise to significantly higher levels of peripheral blood myeloid $\left(\mathrm{Mac}^{+} \mathrm{1}^{+}\right.$or $\left.\mathrm{Gr}-\mathrm{1}^{+}, A, B\right)$, erythroid $\left(\right.$ Ter $\left.119^{+}, C\right)$ and platelet $\left(\mathrm{CD} 41^{+}, D\right)$ reconstitution as compared with control virus-infected cells. MSCV-Sox17 but not MSCV-Sox17his virus-infected cells also exhibited significantly enhanced B-cell $\left(\mathrm{B} 220^{+} ; E\right)$ reconstitution but no significant differences were observed in the levels of T-cell $\left(\mathrm{CD}^{+} ; F\right)$ reconstitution. The data in $A-F$ reflect three independent experiments with a total of nine to14 recipients per treatment. $\left(^{\star}\right) P<0.05 ;\left(^{\star \star}\right) P<0.01 .(G)$ Eighty-nine percent (eight of nine) of mice transplanted with MSCV-Sox17his-infected cells and $100 \%$ of mice transplanted with MSCV-Sox17-infected cells exhibited long-term multilineage reconstitution by donor $\mathrm{GFP}^{+}$ cells. In contrast, only $36 \%$ (five of 14) of recipients transplanted with control virus-infected cells showed long-term multilineage reconstitution. $(H)$ Ectopic Sox17 expression significantly increased the ratio of myeloid $\left(\mathrm{Mac}^{-} 1^{+}\right)$to lymphoid $\left(\mathrm{B} 220^{+}\right.$or $\left.\mathrm{CD}^{+}\right)$cells produced in recipient mice at $16 \mathrm{wk}$ after transplantation. $\left(^{*}\right) P<0.05$. $(I)$. Representative Wright-Giemsa stains of blood from E14 and adult wild-type mice, as well as primary recipients of MSCV-GFP or MSCVSox17 virus-infected adult bone marrow cells. Ectopic Sox17 expression did not lead to the appearance of nucleated red blood cells characteristic of primitive erythropoiesis.

normal adult bone marrow, where $21 \% \pm 3 \%$ of cells were lymphoid.

Primary recipient mice reconstituted with Sox17expressing cells had significantly larger spleens than mice reconstituted with control cells (Fig. 3A,B). This was at least partly because of increased donor erythropoiesis and thrombopoiesis in the spleens of mice that received Sox17-expressing cells (Fig. 3C,D). Hematopoietic neoplasms were rarely evident within 16 wk of transplantation in primary recipient mice. The frequencies of $\mathrm{GFP}^{+} \mathrm{B}$ and $\mathrm{T}$ cells in the spleens of mice that received Sox17expressing cells were significantly reduced as compared with recipients of control cells (Fig. 3C,E). Therefore, Sox17-expressing adult cells were reminiscent of fetal hematopoietic cells (Morrison et al. 1995), exhibiting increased reconstituting potential (Fig. 2A-F), an increased frequency of long-term multilineage reconstituting cells (Fig. 2G), and increased nonlymphoid hematopoiesis (Figs. 2A-D, 3A-D) relative to control adult cells.

In addition to altering the levels at which myeloid cells, erythroid cells, platelets, and lymphoid cells were produced, Sox17 expression in adult cells also altered the phenotype of some of these cells to resemble fetal cells.
Myelopoiesis in the fetal liver is phenotypically distinct from adult bone marrow in that most fetal liver Mac- $1^{+}$ cells express lower levels of Gr-1 (Fig. 3F). Recipients of MSCV-GFP-infected control cells exhibited donor myelopoiesis that phenotypically resembled adult hematopoiesis (Fig. 3F). In contrast, recipients of MSCV-Sox17infected cells exhibited donor myelopoiesis that phenotypically resembled fetal liver hematopoiesis (Fig. 3F). Thrombopoiesis in the fetal liver is also phenotypically distinct from bone marrow, as fetal liver contains a pronounced population of c-kit ${ }^{+} \mathrm{CD} 41^{+}$cells that is nearly absent from adult bone marrow (Fig. 3G). Recipients of MSCV-GFP-infected control cells phenotypically resembled adult hematopoiesis, with few $\mathrm{GFP}^{+} \mathrm{c}-\mathrm{kit}^{+} \mathrm{CD} 41^{+}$ cells (Fig. 3G). In contrast, recipients of MSCV-Sox17infected cells had abundant $\mathrm{GFP}^{+} \mathrm{c}-\mathrm{kit}^{+} \mathrm{CD} 41^{+}$cells in a pattern that resembled the fetal liver (Fig. 3G). These MSCV-Sox17-infected c-kit ${ }^{+} \mathrm{CD} 41^{+}$cells uniformly expressed CD45 and up-regulated CD42d expression as they acquired CD41 expression (Fig. $3 \mathrm{H}$ ), as would be expected of megakaryocyte progenitors. Sox17-expressing adult cells give rise to hematopoiesis that resembles fetal liver hematopoiesis in multiple phenotypic and functional respects. 


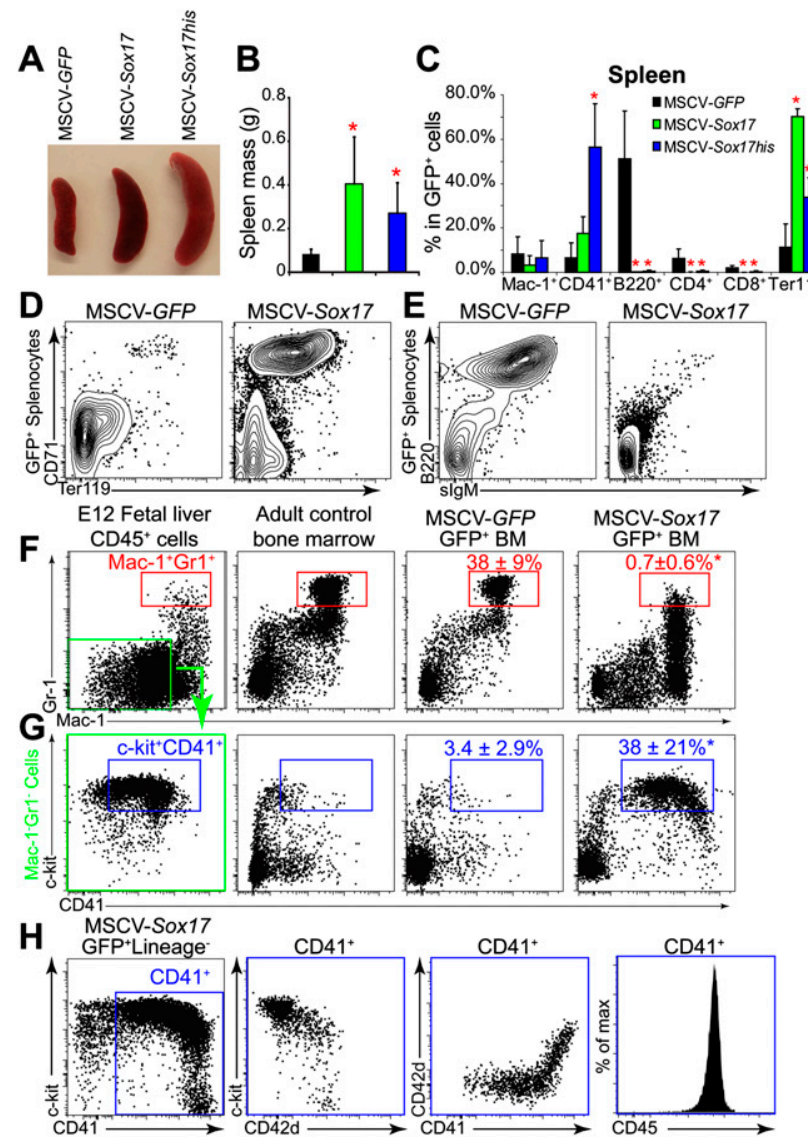

Figure 3. Ectopic Sox17 expression in adult bone marrow cells biased hematopoiesis in adult recipient mice to resemble fetal hematopoiesis. Representative images of the spleens of primary recipient mice reconstituted with adult bone marrow cells infected with MSCV-GFP control virus, MSCV-Sox17, or MSCV-Sox17his virus (16 wk after transplantation). Sox17 expression significantly increased spleen size $(A)$ and mass $(B)$ as a consequence of extramedullary hematopoiesis (splenic architecture was normal and erythropoiesis was evident). (C) Sox17 expression significantly increased the frequency of Ter $119^{+}$ erythroid cells and $\mathrm{CD}_{4} 1^{+}$megakaryocyte lineage cells in the spleen, and significantly reduced the frequencies of $\mathrm{B} 220^{+} \mathrm{B}$ cells and $\mathrm{CD}^{+}$or $\mathrm{CD} 8^{+} \mathrm{T}$ cells (four independent experiments with a total of four to six mice per treatment; $\left.\left.{ }^{\star}\right] P<0.05\right) .(D, E)$ Representative flow cytometry plots showing increased erythroid cells $\left(D ; \mathrm{CD} 71^{+}\right.$Ter $\left.119^{+}\right)$and decreased B cells $\left(E ; \mathrm{B} 220^{+}\right)$ in the spleens of mice reconstituted by Sox17-expressing cells as compared with control cells. $(F)$ Compared with control cells, Sox17-expressing cells gave rise to significantly fewer Mac$1^{+} \mathrm{Gr}-1^{+}$myeloid cells, and myelopoiesis from Sox17-expressing cells phenotypically resembled fetal liver rather than adult bone marrow. (Numbers indicate the percentage of all $\mathrm{GFP}^{+}$bone marrow cells that were $\mathrm{Mac}-1^{+} \mathrm{Gr}-1^{+}$.) $(G)$ Compared with control cells, Sox17-expressing cells gave rise to significantly more c-kit ${ }^{+} \mathrm{CD} 41^{+}$megakaryocyte lineage cells, and thrombopoiesis by Sox17-expressing cells phenotypically resembled the fetal liver rather than adult bone marrow. (Numbers indicate the percentage of all $\mathrm{GFP}^{+}$bone marrow cells that were c-kit ${ }^{+} \mathrm{CD} 41^{+}$.) (H) All Sox17-expressing c-kit ${ }^{+} \mathrm{CD} 41^{+}$cells in primary recipients expressed CD45, and some expressed the megakaryocyte marker CD42d. (CD41 was excluded from the lineage cocktail in this experiment.)

\section{Sox17 expression confers fetal HSC properties upon adult hematopoietic progenitors}

We assessed the effects of ectopic Sox17 expression on adult HSCs and other immature hematopoietic progenitors in recipient mice $16 \mathrm{wk}$ after transplantation of retrovirally infected donor cells. In recipients of MSCVSox17-infected cells, we observed a trend toward lower frequencies of $\mathrm{GFP}^{+} \mathrm{CD} 150^{+} \mathrm{CD} 48^{-}$LSK HSCs in the bone marrow and spleen as compared with recipients of MSCVGFP-infected control cells (Fig. 4A,B). This effect was not statistically significant due to variability among control mice, but Sox17-expressing CD150 ${ }^{+} \mathrm{CD} 48^{-}$LSK cells were nonetheless so scarce in recipients of MSCV-Sox17infected cells $\left(<0.001 \%\right.$ of $\mathrm{GFP}^{+}$cells) (Fig. 4A,B) that it was not possible to isolate enough of these cells for

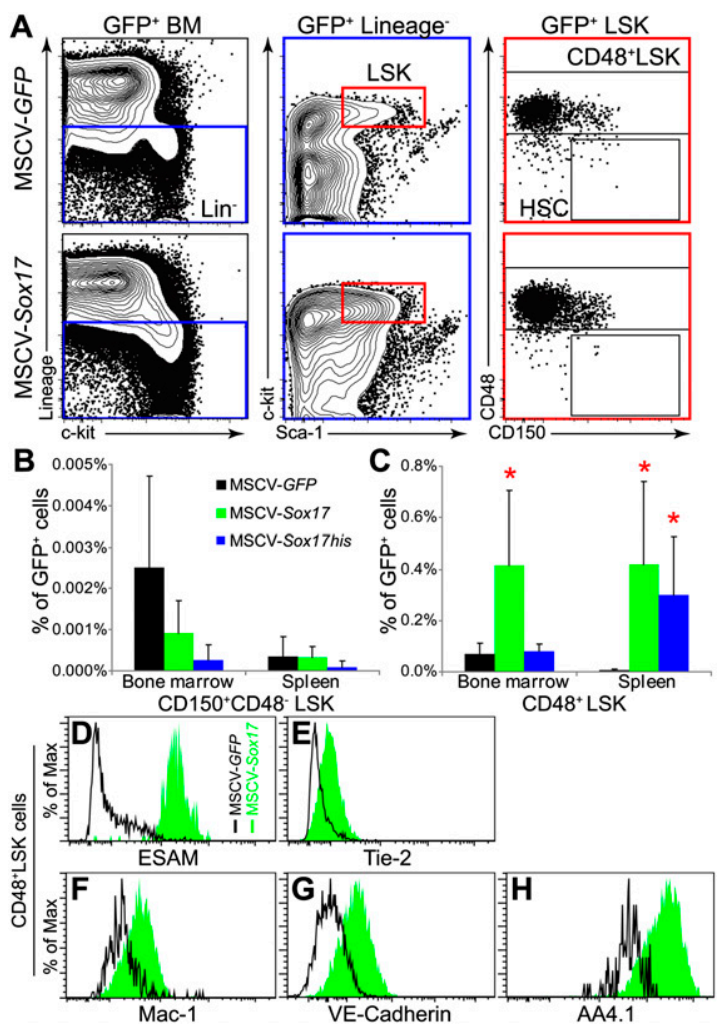

Figure 4. Ectopic Sox17 expression in adult bone marrow cells expanded CD48 ${ }^{+}$LSK hematopoietic progenitors and induced the expression of fetal HSC markers by these cells. (A) Representative flow cytometry plots of $\mathrm{GFP}^{+}$bone marrow cells in primary recipient mice transplanted with MSCV-GFP control virus or MSCV-Sox17-infected bone marrow cells. $(A-C)$ Sox17expressing cells gave rise to a significantly higher frequency of LSK cells and CD $48^{+}$LSK cells as compared with control cells in the bone marrow and spleen (shown in $A, C)\left({ }^{\star}\right) P<0.05$; five to seven independent experiments. $(B)$ The frequency of $\mathrm{GFP}^{+}$ CD150 ${ }^{+}$CD $48^{-}$LSK HSCs was lower in recipients of Sox17expressing cells as compared with control cells, although the difference was not statistically significant. $(D-H)$ Compared with control CD $48^{+}$LSK cells, Sox17-expressing CD $48^{+}$LSK cells exhibited increased expression of the HSC markers ESAM $(D)$ and Tie-2 $(E)$, as well as the fetal HSC markers Mac-1 $(F)$, VECadherin $(G)$, and AA4.1 $(H)$. 
further analysis. In contrast, we observed a significantly higher frequency of $\mathrm{GFP}^{+} \mathrm{CD} 48^{+} \mathrm{LSK}$ cells in the bone marrow and spleen of recipients of MSCV-Sox17-infected cells as compared with recipients of MSCV-GFP-infected control cells (Fig. 4A,C). The data thus suggest that ectopic Sox17 expression in adult bone marrow cells leads to the expansion of immature hematopoietic progenitors.

We examined the developmental potential of CD $48^{+}$LSK cells isolated from normal adult mice. We transplanted 100,500 , or 2500 CD $48^{+}$LSK cells from normal donor mice into irradiated recipient mice. The donor CD $48^{+}$LSK cells gave rise to transient multilineage reconstitution in myeloid, erythroid, platelet, B-cell, and T-cell lineages (Supplemental Fig. 3). Myeloid lineage reconstitution, the most acute indicator of ongoing donor hematopoiesis in the bone marrow, peaked $\sim 2$ wk after transplantation and could no longer be detected by 6-8 wk after transplantation. In recipients transplanted with 100 or 500 CD48 ${ }^{+}$LSK cells, one of three and four of four recipients, respectively, exhibited transient multilineage reconstitution, with peak donor cell reconstitution of $1.7 \% \pm 0.3 \%$ or $7.4 \% \pm 1.6 \%$ of white blood cells at $3 \mathrm{wk}$ after transplantation (Supplemental Fig. 3). These results indicate that in normal adult mice the CD $48^{+}$LSK cell population contains transiently reconstituting progenitors that give very low levels of multilineage reconstitution and have little or no selfrenewal potential.

To understand the consequences of ectopic Sox17 expression in adult CD $48^{+}$LSK cells, we first examined the effects on cell phenotype. Sox17-expressing CD48 ${ }^{+}$LSK cells were phenotypically different from fetal and adult HSCs in that they were positive for CD48 (Fig. 4A). However, Sox17-expressing CD $48^{+}$LSK cells expressed a number of other HSC markers at higher levels than control (GFP-expressing) CD48 ${ }^{+}$LSK cells, including epithelialspecific adhesion molecule (ESAM) (Fig. 4D) and Tie-2 (Fig. 4E), which mark fetal and adult HSCs (Yano et al. 1997; Hsu et al. 2000; Yokota et al. 2009). Sox17-expressing CD $48^{+}$LSK cells also expressed several fetal HSC markers more highly than control CD48 ${ }^{+}$LSK cells, including Mac-1 (Fig. 4F) and VE-Cadherin (Fig. 4G), which are expressed by fetal but not by adult HSCs (Morrison et al. 1995; Kim et al. 2005), and AA4.1 (Fig. 4H), a fetal HSC marker (Jordan et al. 1990). Sox17-expression therefore caused adult CD $48^{+}$LSK cells to acquire a phenotype that was similar, but not identical, to fetal HSCs.

To assess the reconstituting potential of Sox17-expressing CD $48^{+}$LSK cells, we isolated these cells or whole bone marrow cells from recipient mice that had been reconstituted by MSCV-Sox17-infected cells or MSCV-GFPinfected control cells and transplanted these cells into secondary recipient mice. We first transplanted 1 million unfractionated whole bone marrow cells from recipients of Sox17-expressing or control cells into irradiated recipient mice along with 200,000 recipient bone marrow cells for radioprotection. Three of four recipients transplanted with control bone marrow cells were long-term multilineage-reconstituted by $\mathrm{GFP}^{+}$cells (Fig. 5A,C). Nine of 11 recipients of Sox17-expressing bone marrow cells also showed long-term multilineage reconstitution, at least in erythroid, myeloid, and platelet lineages (Fig. $5 \mathrm{~A}, \mathrm{C})$. Consistent with the results in primary recipient mice (Fig. 2), the Sox17-expressing bone marrow cells tended to give higher levels of myeloid, erythroid, and platelet reconstitution, but lower levels of B- and T-lineage reconstitution, compared with control cells (Fig. 5A).

We also transplanted $50 \mathrm{GFP}^{+} \mathrm{CD} 48^{+} \mathrm{LSK}$ cells from recipients of Sox17-expressing or control cells into irradiated recipient mice along with 200,000 recipient bone marrow cells for radioprotection. Consistent with results from CD $48^{+}$LSK cells obtained from normal adult mice (Supplemental Fig. 3), almost all recipients (eight of nine, $89 \%$ ) transplanted with MSCV-GFP-infected control CD $48^{+}$LSK cells exhibited transient multilineage reconstitution by $\mathrm{GFP}^{+}$myeloid, erythroid, and lymphoid cells (Fig. 5B,C). In contrast, 14 of 15 recipients transplanted with Sox17-expressing CD $48^{+}$LSK cells showed longterm reconstitution by $\mathrm{GFP}^{+}$erythroid cells, and most of these mice also showed long-term reconstitution by $\mathrm{GFP}^{+}$myeloid cells and platelets (Fig. 5B,C). In the erythroid lineage, Sox17-expressing CD $48^{+}$LSK cells gave significantly higher levels of reconstitution than control CD $48^{+}$LSK cells; however, Sox17-expressing CD48 ${ }^{+}$LSK cells generally did not give rise to detectable lymphoid reconstitution (Fig. 5B). Sox17 expression in adult CD $48^{+}$LSK cells confers the ability to give long-term multilineage reconstitution in the myeloid, erythroid, and platelet lineages. In these respects, Sox17-expressing CD $48^{+}$LSK cells had properties similar to fetal HSCs, although they were not functionally identical, as fetal HSCs yield higher levels of lymphoid reconstitution. It is not clear whether Sox17-expressing CD48 ${ }^{+}$LSK cells lack lymphoid potential, or whether the constitutive ectopic expression of Sox17 from the viral vector impairs the differentiation or survival of lymphoid lineage progenitors.

\section{Ectopic Sox17 expression is sufficient to confer long-term self-renewal potential}

To test whether SOX17 acts directly on transiently reconstituting hematopoietic progenitors to increase their selfrenewal potential, we isolated $\mathrm{CD} 150^{+} \mathrm{CD} 48^{-}$LSK HSCs (Kiel et al. 2005b), CD150- CD48 ${ }^{-}$LSK transiently reconstituting MPPs (Kiel et al. 2008), CD48 ${ }^{+}$LSK cells, GMPs ( Lin $^{-} \mathrm{Sca}-1^{-} \mathrm{c}-\mathrm{kit}^{+} \mathrm{Fc} \gamma \mathrm{R}^{+}$cells) (Akashi et al. 2000), and Pre-MegE megakaryocyte-erythrocyte progenitors $\left(\mathrm{Lin}^{-} \mathrm{Sca}-1^{-} \mathrm{c}^{-} \mathrm{kit}^{+} \mathrm{CD} 150^{+} \mathrm{CD} 105^{-}\right)$(Pronk et al. 2007) from adult bone marrow and infected these cells with MSCV-GFP or MSCV-Sox17 retroviruses. We then transplanted the infected cells into irradiated recipient mice along with 200,000 recipient bone marrow cells to assess their reconstituting potential. The gating strategies used to flow-cytometrically isolate each cell population and the viral infection efficiencies of each cell population prior to transplantation are shown in Supplemental Figure 4.

To assess the effects of ectopic Sox17 expression on adult HSCs, we sorted 500 HSCs per well of a 96-well plate, infected with MSCV-GFP or MSCV-Sox17 over a 48-h period, then transplanted the entire contents of each well into an irradiated mouse along with 200,000 


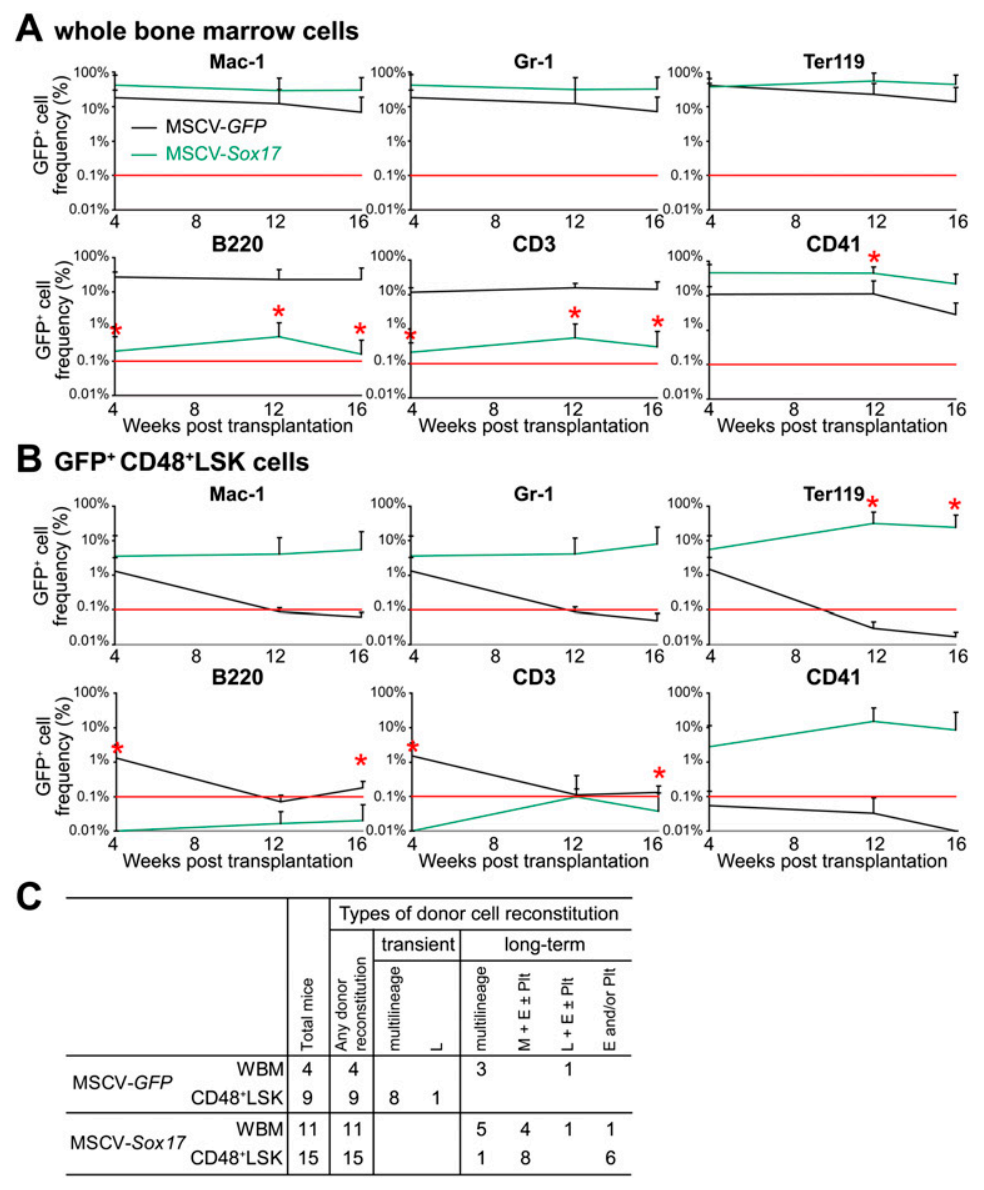

Figure 5. Adult CD48 ${ }^{+}$LSK cells give only low levels of transient multilineage reconstitution, but ectopic Sox17 expression in these cells confers the potential to give long-term multilineage reconstitution. (A) One-million unfractionated whole bone marrow cells from primary recipients of MSCV-GFP-infected control cells or MSCVSox17-infected cells were transplanted into lethally irradiated secondary recipients along with 200,000 radioprotective recipient bone marrow cells. Sox17-expressing cells gave rise to higher levels of long-term reconstitution in the myeloid (Mac-1 and Gr-1), erythroid (Ter119), and megakaryocyte (CD41) lineages, but significantly lower levels of reconstitution in the B-cell (B220) and T-cell (CD3) lineages. Data represent mean \pm SD from four to 11 recipients per treatment; $\left({ }^{\star}\right) P<0.05$; note that red lines indicate background, below which donor cell reconstitution cannot be detected. (B). Fifty $\mathrm{GFP}^{+} \mathrm{CD} 48^{+} \mathrm{LSK}$ cells from primary recipients of MSCVGFP-infected control cells or MSCV-Sox17-infected cells were transplanted into lethally irradiated secondary recipients along with 200,000 recipient bone marrow cells. While control CD48 ${ }^{+}$LSK cells gave only low levels of transient multilineage reconstitution in the myeloid, erythroid, and lymphoid lineages, Sox17-expressing CD $48^{+}$LSK cells gave rise to long-term multilineage reconstitution in the myeloid, erythroid, and megakaryocyte, but not the B- or T-cell lineages. The data represent mean \pm SD from nine to 15 recipients per treatment; $\left({ }^{*}\right)$ $P<0.05$. $(C)$ Control CD $48^{+}$LSK cells gave rise to transient multilineage reconstitution in almost all recipients (eight of nine), whereas Sox17-expressing CD48 ${ }^{+}$LSK cells gave rise to long-term multilineage reconstitution in the erythroid and megakaryocyte lineages in most recipients (14 of 15 mice) and often in the myeloid lineage as well (nine of 15 mice). recipient bone marrow cells. Of 19 mice transplanted with MSCV-GFP-infected control HSCs, 11 exhibited transient multilineage reconstitution (Fig. 6C; Supplemental Fig. 5A). It is common to observe transient reconstitution by HSCs that have been cultured, because culture induces HSCs to exit the stem cell pool. Of 16 mice transplanted with MSCV-Sox17-infected HSCs, nine exhibited long-term multilineage reconstitution and two others exhibited long-term erythroid, myeloid, and platelet reconstitution (Fig. 6C; Supplemental Fig. 5A). The levels of donor cell reconstitution by MSCV-Sox17infected HSCs were also significantly higher than from MSCV-GFP-infected HSCs in the myeloid, erythroid, and platelet lineages $(P<0.05)$ (Supplemental Fig. 5A). These results suggest that Sox17 increases the reconstituting capacity of HSCs.

To assess the effects of ectopic Sox17 expression on adult MPPs, we sorted 500 MPPs per well of a 96-well plate infected with MSCV-GFP or MSCV-Sox17 over a 48-h period and transplanted the entire contents of each well into an irradiated mouse along with 200,000 recipient bone marrow cells. Of 13 mice transplanted with MSCVGFP-infected control MPPs, five exhibited transient multilineage reconstitution and five exhibited transient lymphoid reconstitution with or without erythroid and/or platelet reconstitution (Fig. 6A,C). Of 15 mice trans- planted with MSCV-Sox17-infected MPPs, five exhibited long-term multilineage reconstitution and four exhibited transient or long-term erythroid and/or platelet reconstitution (Fig. 6A,C). MSCV-Sox17-infected MPPs gave rise to higher levels of donor cell reconstitution in all lineages, although at $16 \mathrm{wk}$ after transplantation, the difference was only statistically significant in the erythroid and B-cell lineages (Fig. 6A). These results suggest that Sox17 can increase the reconstituting capacity of MPPs and confer long-term self-renewal potential.

To assess the effects of ectopic Sox17 expression on adult CD48 ${ }^{+}$LSK cells, we sorted 500 (12-15 recipients per treatment) or 2000 (five to 10 recipients per treatment) CD $48^{+}$LSK cells per well of a 96-well plate infected with MSCV-GFP or MSCV-Sox17 over a 24-h period and transplanted the entire contents of each well into an irradiated mouse along with 200,000 recipient bone marrow cells. Of 20 mice transplanted with MSCV-GFPinfected control CD48 ${ }^{+}$LSK cells, seven showed various types of transient reconstitution but none exhibited detectable long-term donor cell reconstitution (Fig. 6B,C). Of 22 mice transplanted with MSCV-Sox17-infected CD $48^{+}$LSK cells, one exhibited long-term multilineage reconstitution and eight exhibited long-term reconstitution in the myeloid, erythroid, and/or platelet lineages (Fig. $6 \mathrm{~B}, \mathrm{C})$. Given that some mice were long-term reconstituted 


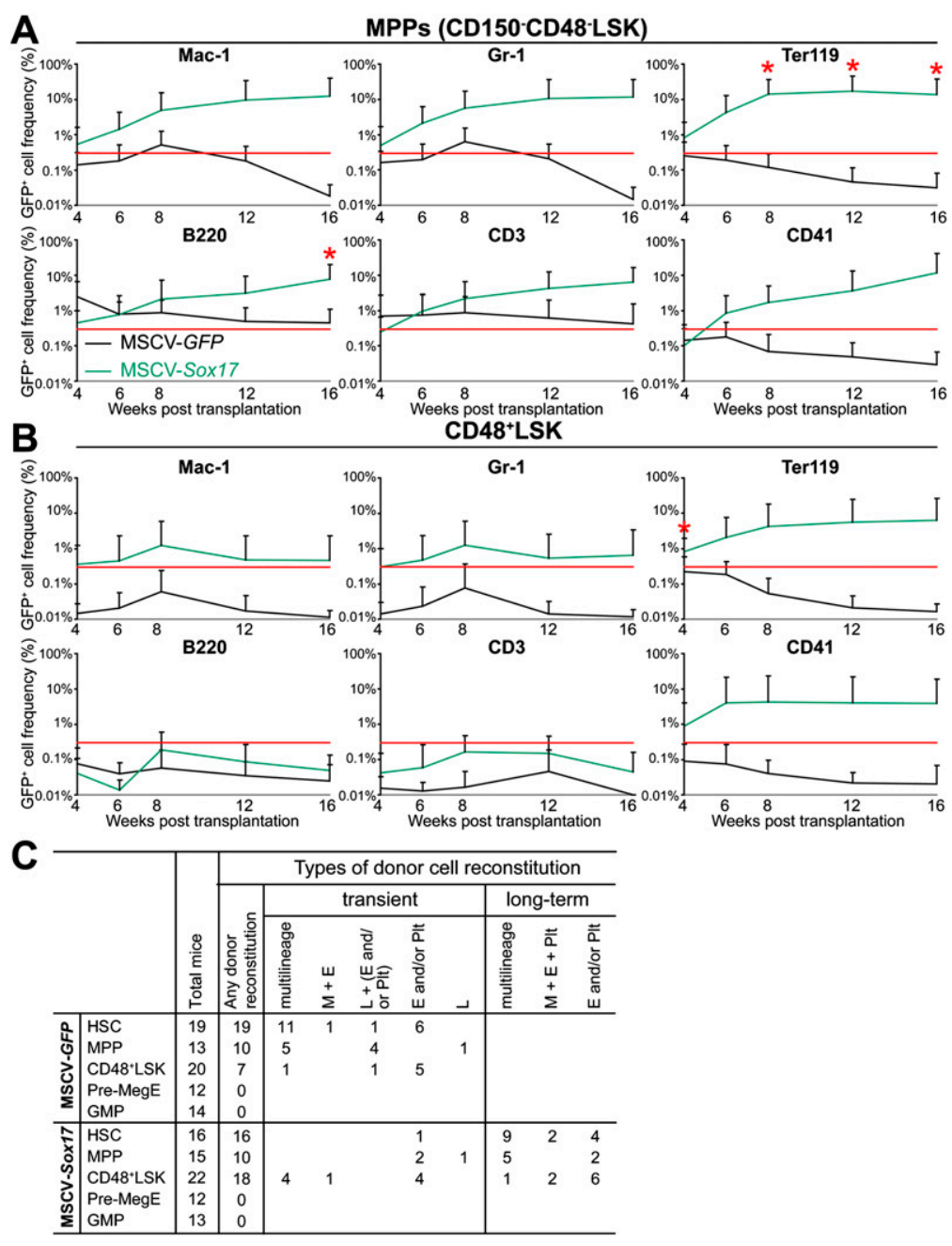

Figure 6. Ectopic Sox17 expression in adult transiently reconstituting multipotent progenitors conferred long-term self-renewal potential. $(A)$ Fivehundred adult bone marrow MPPs $\left(\mathrm{CD} 150^{-} \mathrm{CD} 48^{-} \mathrm{LSK}\right.$ cells) were infected with MSCV-GFP control or MSCVSox 17 virus and transplanted into lethally irradiated recipient mice along with 200,000 recipient bone marrow cells. While control MPPs gave transient multilineage reconstitution in most recipient mice $(A, C)$, Sox17-expressing MPPs gave long-term multilineage reconstitution in five of 10 recipients and long-term erythroid and/or platelet reconstitution in another two recipients $(C)$. Data represent mean \pm SD from 13-15 recipients per treatment; $\left.{ }^{*}\right) P<$ 0.05 . (B) Five-hundred or $2000 \mathrm{CD}^{4} 8^{+} \mathrm{LSK}$ adult bone marrow cells were infected with MSCV-GFP control or MSCV-Sox17 virus and transplanted into lethally irradiated recipient mice along with 200,000 recipient bone marrow cells. These data reflect mean \pm SD from 20-22 recipients per treatment; $\left.\left.\right|^{*}\right) P<0.05$. While control CD48 ${ }^{+}$LSK cells gave transient multilineage reconstitution (in various combinations of lineages) in all recipient mice that showed donor cell reconstitution $(B, C)$, Sox17-expressing CD $48^{+}$LSK cells gave long-term reconstitution in various combinations of lineages in nine of 22 recipient mice and transient multilineage reconstitution (five of 22) or transient erythroid and/or platelet reconstitution in the remaining reconstituted recipients (four of $22 ; C$ ). (C) No cell population infected with MSCVGFP control virus gave long-term reconstitution in any combination of lineages. In contrast, nine of 16, five of 15, and one of 22 recipients of MSCVSox17-infected HSCs, MPPs, or CD $48^{+}$LSK cells showed long-term multilineage reconstitution, respectively, and, in total, 15 of 16 , seven of 15 , and nine of 22 recipients of Sox17-expressing HSCs, MPPs, or $\mathrm{CD} 48^{+}$LSK cells showed longterm reconstitution in the myeloid and/or erythroid lineages. Donor cell reconstitution by control and Sox17-expressing HSCs, GMPs, and Pre-MegEs can be found in Supplemental Figure 5.

by MSCV-Sox17-infected CD48+LSK cells but no mice were detectably long-term reconstituted by MSCV-GFPinfected control CD48 ${ }^{+}$LSK cells, these results suggest that Sox17 increases the reconstituting capacity of CD $48^{+}$LSK cells and confers long-term self-renewal potential.

We performed similar experiments in which GMPs and Pre-MegE cells were infected with MSCV-GFP or MSCVSox17 retroviruses and transplanted into irradiated mice; however, neither the MSCV-GFP-infected nor the MSCVSox17-infected cells gave any detectable donor cell reconstitution in irradiated mice (Supplemental Fig. 5B,C). Overall, the data suggest that ectopic expression of Sox17 in adult HSCs and MPPs, but not restricted progenitors, can increase the reconstituting activity and self-renewal of these cells.

To test whether Sox17-expressing adult HSCs, MPPs, or CD $48^{+}$LSK cells could be serially transplanted, we transplanted 200,000 whole bone marrow cells from primary recipients long-term reconstituted by MSCV-
Sox17-infected HSCs, MPPs, or CD48 ${ }^{+}$LSK cells, together with 200,000 recipient bone marrow cells, into irradiated secondary recipients. The contribution of $\mathrm{GFP}^{+}$donor cells to the peripheral blood was assessed $16 \mathrm{wk}$ after transplantation (Supplemental Fig. 6A). Three of three secondary recipients of whole bone marrow cells from primary recipients of MSCV-Sox17-infected HSCs exhibited long-term reconstitution in the myeloid, erythroid, and platelet lineages (Supplemental Fig. 6B). Five of 10 secondary recipients of whole bone marrow cells from primary recipients of MSCV-Sox17-infected MPPs exhibited long-term multilineage reconstitution in all blood lineages (Supplemental Fig. 6B). Four of four secondary recipients of whole bone marrow cells from primary recipients of MSCV-Sox17 virus-infected CD48 ${ }^{+}$LSK cells exhibited long-term multilineage reconstitution in all blood lineages (Supplemental Fig. 6B). These data indicate that Sox17-expressing HSCs, MPPs, and CD48 ${ }^{+}$LSK cells were capable of long-term self-renewal, including reconstitution of secondary recipients. 
Sox17 expression in adult progenitors increases the expression of fetal HSC genes

We compared the gene expression profiles of E16.5 fetal liver HSCs, young adult bone marrow HSCs, young adult bone marrow CD48 ${ }^{+}$LSK cells, and Sox17-expressing CD48 ${ }^{+}$LSK cells isolated from mice that had been transplanted with MSCV-Sox17-infected bone marrow cells 12 wk earlier. We first generated custom gene sets (Supplemental Table 2) enriched in adult HSCs (genes that were significantly $[P<0.05]$ up-regulated by at least twofold in adult HSCs as compared with CD $48^{+}$LSK cells), adult progenitors (genes that were significantly up-regulated by at least twofold in CD48 ${ }^{+}$LSK cells as compared with adult HSCs), or fetal liver HSCs (genes that were significantly up-regulated by at least twofold in fetal HSCs as compared with adult HSCs). We performed gene set enrichment analysis (GSEA) to assess whether ectopic Sox 17 expression in adult CD $48^{+}$LSK progenitors caused global changes in gene expression that resembled fetal or adult HSCs. When we compared Sox17-expressing with control CD $48^{+}$LSK cells, we found that Sox17 expression increased the expression of many, but not all, genes associated with adult HSCs (false discovery rate [FDR] $q<0.001$ ) (Fig. 7A) and fetal HSCs (FDR $q=0.001$ ) (Fig. 7C). Sox17 expression decreased the expression of most genes associated with $\mathrm{CD} 48^{+} \mathrm{LSK}$ progenitors (FDR $q<$ 0.001) (Fig. 7B). These results were confirmed by repeating the GSEA using independent HSC and progenitor gene sets generated by others (Supplemental Fig. 7A-D).

A gene-by-gene analysis confirmed that ectopic Sox17 expression in adult hematopoietic progenitors caused global changes in gene expression that caused CD $48^{+}$LSK progenitors to more closely resemble HSCs (see Supplemental Table 3 for a complete list of genes that were differentially expressed between Sox17-expressing and control CD $48^{+}$LSK cells). Of 376 genes that were significantly more highly expressed (more than twofold upregulated, $P<0.051$ in Sox17-expressing as compared with control CD48 ${ }^{+}$LSK cells, 91 were also more highly expressed in control HSCs as compared with control CD48 ${ }^{+}$LSK cells (Fig. 7D). Only seven of these genes were more highly expressed in control CD48 ${ }^{+}$LSK cells as compared with HSCs (Fig. 7D). Of 264 genes that were expressed at significantly lower levels (more than twofold down-regulated, $P<0.05)$ in Sox17-expressing as compared with control CD $48^{+}$LSK cells, only 13 were more highly expressed in control HSCs as compared with control CD $48^{+}$LSK cells (Fig. 7D). One-hundred-twentytwo of these genes were more highly expressed in control CD48 ${ }^{+}$LSK cells as compared with HSCs (Fig. 7D). Many genes associated with HSCs were thus up-regulated and many genes associated with downstream progenitors were down-regulated upon Sox17 expression in CD $48^{+}$LSK cells.

We performed a similar analysis on a smaller group of genes whose expression changed by at least fivefold in Sox17-expressing as compared with control CD $48^{+}$LSK cells. Of the 82 genes that were most highly expressed (more than fivefold up-regulated, $P<0.05$ ) in Sox17- expressing as compared with control CD $48^{+}$LSK cells, more of these genes were preferentially expressed in control HSCs (21) as compared with control CD48 ${ }^{+}$LSK cells (four) (Fig. 7E). The remaining 57 genes were not differentially expressed among HSCs and CD $48^{+}$LSK cells (Fig. 7E). Among the 82 genes that were most up-regulated in Sox17-expressing CD $48^{+}$LSK cells, more of these genes were also preferentially expressed by fetal HSCs (17) as compared with adult HSCs (five). Of the 33 genes that were most down-regulated (more than fivefold, $P<$ 0.05) in Sox17-expressing as compared with control CD $48^{+}$LSK cells, none were preferentially expressed by HSCs, while 18 were preferentially expressed by CD $48^{+}$LSK cells (Fig. 7E). The remaining 15 genes were not differentially expressed among HSCs and CD48 ${ }^{+}$LSK cells (Fig. 7E). Among the 33 genes that were most downregulated in Sox17-expressing CD $48^{+}$LSK cells, 16 were also differentially expressed between fetal and adult HSCs, and most of these (12) were more highly expressed by adult HSCs. Ectopic Sox 17 expression in adult CD $48^{+}$LSK cells therefore strongly increased the expression of genes associated with fetal HSCs while strongly reducing the expression of genes associated with adult stem/progenitor cells.

Genes that were more highly expressed by fetal HSCs and that were up-regulated by Sox17 expression in CD $48^{+}$LSK cells included Cdh5 (encodes VE-Cadherin), Rasgrp3 (Ras guanyl-releasing protein 3), Egfl7 (encodes VE-statin), Ctnnal1 ( $\alpha$-catulin), and Hbb-b1 (hemoglobin$\beta 1)$ (Fig. 7F; Supplemental Tables 2,3). A number of genes that encode factors that promote HSC maintenance were also significantly increased by Sox17 expression in CD48 ${ }^{+}$LSK cells, including Evi-1 (Goyama et al. 2008), Gata-2 (Tsai et al. 1994; Rodrigues et al. 2005), Pbx1 (Ficara et al. 2008), Egr1 (Min et al. 2008), and Tie2 (Puri and Bernstein 2003; Arai et al. 2004) (Fig. 7F; Supplemental Table 3). Gata-2 and Evi-1 promote HSC self-renewal in a dosage-sensitive manner (Rodrigues et al. 2005; Goyama et al. 2008) such that increased expression of these transcription factors could contribute to the increased self-renewal of CD $48^{+}$LSK cells. Finally, several genes that were up-regulated in differentiating hematopoietic cells as compared with HSCs were reduced in expression within Sox17-expressing CD48 ${ }^{+}$LSK cells, including Recombinase-activating gene 1 (Rag1), Rag2, and Dntt (Fig. 7F; Supplemental Table 2). Rag1 and Rag2 are required for lymphocyte differentiation (Mombaerts et al. 1992; Shinkai et al. 1992), potentially contributing to the defects in lymphopoiesis from Sox17-expressing stem/ progenitor cells.

We also performed GSEA on Sox17-expressing versus control CD48 ${ }^{+}$LSK cells using gene sets for WNT pathway components and WNT targets curated by the Broad Institute (Supplemental Fig. 7E,F). However, we did not observe a significant enrichment of either WNT pathway components (FDR $q=0.13$ ) (Supplemental Fig. 7E) or WNT target genes (FDR $q=0.27$ ) (Supplemental Fig. 7F) in control or Sox17-expressing CD $48^{+}$LSK cells. We therefore did not find any evidence that ectopic Sox17 expression in adult hematopoietic progenitors alters WNT signaling. 

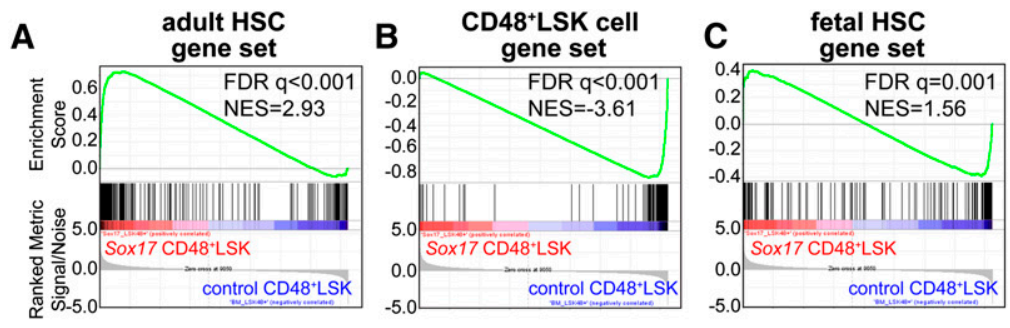

D

\begin{tabular}{l|c|ccc|ccc}
\hline & \multicolumn{6}{|c}{ \# of genes } \\
\cline { 2 - 8 } & \multirow{2}{*}{ Total } & \multicolumn{1}{|c|}{ HSC vs. CD48+LSK } & \multicolumn{2}{|c}{ FL HSC vs. BM HSC } \\
\cline { 2 - 8 } & & UP & DOWN & N.C. & UP & DOWN & N.C. \\
\hline Genes upregulated in & 376 & 91 & 7 & 278 & 29 & 32 & 315 \\
\cline { 2 - 8 } $\begin{array}{l}\text { Sox17-CD48+LSK cells } \\
\text { (Fold }>2 ; p<0.05)\end{array}$ & $100 \%$ & $24 \%$ & $2 \%$ & $74 \%$ & $8 \%$ & $8 \%$ & $84 \%$ \\
\hline $\begin{array}{l}\text { Genes downregulated in } \\
\text { Sox17-CD48+LSK cells } \\
\text { (Fold }>2 ; p<0.05)\end{array}$ & 264 & 13 & 122 & 129 & 33 & 40 & 191 \\
\cline { 2 - 8 } & $100 \%$ & $5 \%$ & $46 \%$ & $49 \%$ & $13 \%$ & $15 \%$ & $72 \%$ \\
\hline
\end{tabular}

E

\begin{tabular}{l|c|ccc|ccc}
\hline & \multicolumn{7}{|c}{ \# of genes } \\
\cline { 2 - 8 } & \multirow{2}{*}{ Total } & \multicolumn{3}{|c}{ HSC vs. CD48+LSK } & \multicolumn{2}{c}{ FL HSC vs. BM HSC } \\
\cline { 2 - 8 } & & UP & DOWN & N.C. & UP & DOWN & N.C. \\
\hline Genes upregulated in & 82 & 21 & 4 & 57 & 17 & 5 & 60 \\
\cline { 2 - 8 } $\begin{array}{l}\text { Sox17-CD48+LSK cells } \\
\text { (Fold }>5 ; p<0.05)\end{array}$ & $100 \%$ & $26 \%$ & $5 \%$ & $69 \%$ & $21 \%$ & $6 \%$ & $73 \%$ \\
\hline Genes downregulated in & 33 & 0 & 18 & 15 & 4 & 12 & 17 \\
\cline { 2 - 8 } $\begin{array}{l}\text { Sox17-CD48+LSK cells } \\
\text { (Fold }>5 ; p<0.05)\end{array}$ & $100 \%$ & $0 \%$ & $55 \%$ & $45 \%$ & $12 \%$ & $36 \%$ & $52 \%$ \\
\hline
\end{tabular}

$\mathbf{F}$

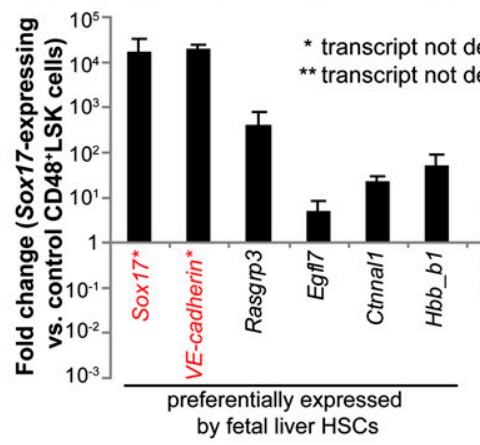

G

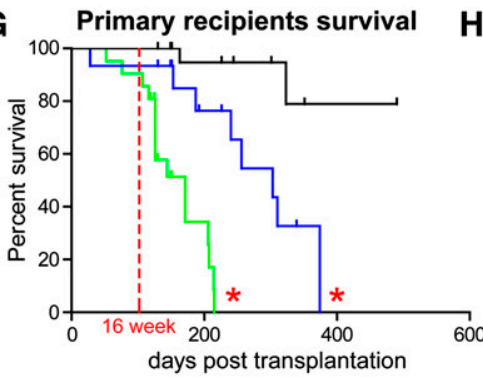

\section{H}

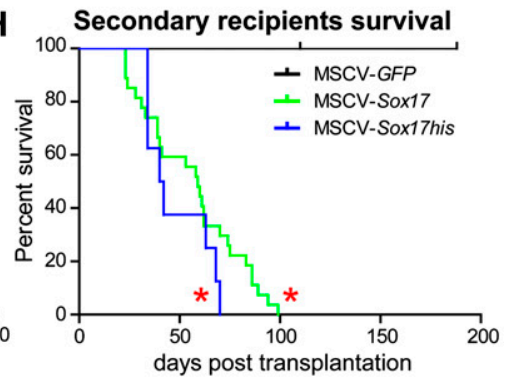

Figure 7. Ectopic Sox17 expression in adult hematopoietic progenitors increased the expression of genes associated with fetal and adult HSCs and reduced the expression of genes associated with differentiation. $(A-C)$ GSEA comparing Sox17expressing (red) versus control bone marrow (blue) CD $48^{+}$LSK cells. Sox17-expressing CD $48^{+}$LSK cells showed significant enrichment of adult HSC (compared with bone marrow CD $48^{+}$LSK cells) and fetal HSC (compared with adult bone marrow HSCs) gene sets $(A, C)$, and significant depletion of a progenitor $\left(\mathrm{CD} 48^{+}\right.$LSK cell compared with HSCs) gene set $(B)$. (NES) Normalized enrichment score. (D) Comparison of the gene expression profiles of Sox17-expressing and control bone marrow CD $48^{+}$LSK cells revealed 376 significantly up-regulated and 264 significantly down-regulated genes in the Sox17expressing cells (fold change $>2$ and $P<0.05$ ). Ninety-one of the 376 up-regulated genes were preferentially expressed by HSCs (compared with bone marrow CD $48^{+}$LSK cells, fold $>2, P<0.05$ ), while 122 of the 264 down-regulated genes were preferentially expressed by $\mathrm{CD} 48^{+} \mathrm{LSK}$ progenitors (compared with HSCs, fold $>2, P<0.05$ ). (E) Using the more stringent cut-off of fold change $>5$ and $P<$ $0.05,82$ genes were up-regulated and 33 genes were down-regulated in Sox17-expressing compared with control CD48 ${ }^{+}$LSK cells. Twenty-one of the 82 upregulated genes were preferentially expressed by adult HSCs as compared with $\mathrm{CD} 48^{+} \mathrm{LSK}$ cells and only four were preferentially expressed by CD $48^{+}$LSK cells. Seventeen of the 82 up-regulated genes were also preferentially expressed by fetal HSCs (compared with bone marrow HSCs), while only five of the 82 genes were preferentially expressed by adult HSCs /compared with fetal HSCs). Most of the down-regulated genes were preferentially expressed by progenitors (relative to HSCs) and by adult (relative to fetal) HSCs. $(F)$ Quantitative RT-PCR of selected genes that were differentially expressed by Sox17-expressing versus control CD $48^{+}$LSK cells by microarray analysis. $\left({ }^{*}\right)$ Transcripts not detected in control CD48 ${ }^{+}$LSK cells after 40 cycles of amplification, fold change was estimated using 35 cycles as the detection limit; $\left({ }^{\star \star}\right)$ transcripts not detected in Sox17-expressing CD $48^{+}$LSK cells after 40 cycles of amplification, fold change was estimated using 35 cycles as the detection limit. Data represents mean \pm SD from three independent experiments. $(G)$. Kaplan-Meier survival curve of primary recipients that received 1 million control or Sox17 virus-infected whole bone marrow cells along with 200,000 bone marrow cells for radioprotection; $\left(^{*}\right) P<0.01$ versus control; $n=15-22$ mice per group. $(H)$ Kaplan-Meier survival curve of secondary recipients that received 3 million whole bone marrow cells from primary recipients in the treatments shown in $G ;\left(^{\star}\right) P<0.01$ versus control; $n=8-27$ mice per group.

We analyzed Sox17 transgenic mice to assess the acute effects of SOX17 expression on HSCs. We used Sox17 transgenic mice $\left[(\text { tetO) })_{7}\right.$ CMVSox17-IRES-NucEGFP $]$ in which Sox17 was expressed under the control of the tetracycline response element and the $C M V$ promoter (Park et al. 2006). When these mice were crossed with
B6.Cg-Gt (ROSA)26Sor ${ }^{\left.\operatorname{tm} 1\left(r t T A{ }^{*} M 2\right)\right) a e} / J$ mice (Hochedlinger et al. 2005), Sox17 expression was widely induced after giving doxycycline in the drinking water. For unknown reasons, all compound Sox 17 transgenic mice died within $7 \mathrm{~d}$ of doxycycline administration; therefore, all analyses of hematopoietic cells from Sox17 transgenic 
mice were performed after 5 or $6 \mathrm{~d}$ of doxycycline treatment. After $5 \mathrm{~d}$ of doxycycline administration, SOX17 was expressed in transgenic LSK cells at 3.1 times the level observed in E12.5 fetal liver LSK cells (Supplemental Fig. 1D). This modest level of SOX17 protein expression in transgenic hematopoietic cells was sufficient to significantly expand LSK cells, phenocopying the effect of retroviral Sox17 overexpression (Supplemental Fig. 8A). GSEA revealed an improved enrichment of fetal HSC genes in Sox17 transgenic as compared with control HSCs (FDR $q<0.001$, normalized enrichment score [NES] = 2.53) (Supplemental Fig. 8B) compared with what we observed in retrovirally infected versus control $\mathrm{CD} 48^{+}$LSK cells (FDR $q=0.001, \mathrm{NES}=1.56$ in Fig. $7 \mathrm{C}$ ). This confirms that ectopic Sox17 expression in adult HSCs increases the expression of fetal HSC genes. We found 23 genes that were significantly up-regulated and only one gene that was significantly down-regulated upon both transgenic and viral overexpression of Sox 17 in adult HSCs or CD $48^{+}$LSK cells (Supplemental Fig. 8D; Supplemental Table 4).

To identify potential downstream mechanisms that could explain the effects of extopic Sox17 expression in adult hematopoietic cells, we performed Gene Ontology (GO) and Pathway analysis on the genes that were significantly changed after retroviral or transgenic Sox17 overexpression (Supplemental Table 5).

\section{Long-term ectopic Sox17 expression leads to leukemogenesis}

A number of genes whose expression was greatly increased by ectopic Sox17 expression are known protooncogenes, including Evi-1 (Buonamici et al. 2004) and Pbx1 (Krosl et al. 1998); therefore, we wondered whether ectopic Sox17 expression in adult hematopoietic stem/ progenitor cells would be leukemogenic. Constitutive ectopic Sox17 expression in adult cells was not sufficient to cause leukemia, as few recipients of Sox17-expressing bone marrow cells exhibited signs of leukemia or died within 4 mo of transplantation (Fig. 7G). However, when recipients of MSCV-Sox17-infected or MSCV-Sox17hisinfected bone marrow cells were aged beyond 4 mo after transplantation, all of the recipients died within 374 $\mathrm{d}$ after transplantation, with features of leukemia (Fig. 7G). Median survival time was $171 \mathrm{~d}$ after transplantation for recipients of MSCV-Sox17-infected bone marrow cells and $303 \mathrm{~d}$ for recipients of MSCV-Sox17his-infected bone marrow cells (Fig. 7G). In contrast, few of the recipient mice reconstituted with MSCV-GFP-infected bone marrow cells died within $490 \mathrm{~d}$ after transplantation, and none of the control mice that died showed signs of leukemia. These results suggest that enforced expression of Sox17 in adult bone marrow cells is not initially leukemogenic, but becomes neoplastic over the long term.

We performed secondary transplants of whole bone marrow cells from moribund primary recipients of Sox17expressing bone marrow cells into irradiated secondary recipients. All secondary recipients died between 23 and $99 \mathrm{~d}$ after transplantation, with a median survival of $59 \mathrm{~d}$ for secondary recipients of MSCV-Sox17-expressing cells and $41 \mathrm{~d}$ for MSCV-Sox17his-expressing cells (Fig. 7H). All of the secondary recipient mice that died showed signs of leukemia, including splenomegaly with infiltrating blast cells and completely effaced splenic architecture.

At the onset of disease, all affected primary recipients exhibited thrombocytopenia, anemia, and/or leukocytosis in peripheral blood, as well as pronounced splenomegaly and/or hepatomegaly (data not shown). Extensive infiltration of undifferentiated blast cells could be seen in the bone marrow, spleen, and liver of affected mice, sometimes also including lung and lymph nodes, disrupting normal tissue architecture (Supplemental Fig. 9A,C). Immunohistochemical staining and flow-cytometric analysis indicated that the blast cells did not express the myeloid markers Mac-1 or Gr-1, the B-cell marker B220, or the T-cell marker CD3 (data not shown), but did express the megakaryocyte markers CD41 and Von Willebrand factor (VWF) (Supplmental Fig. 9B,D). Most blast cells did not appear to express the erythroid marker Ter119 in tissue sections (data not shown), but erythroid cells were nonetheless expanded in number within the spleens of recipient mice with signs of leukemia (Supplemental Fig. 9A). These data suggest that long-term enforced expression of Sox17 leads to the development of a nonlymphoid leukemia with features of megakaryocytic and/or erythroid differentiation (Kogan et al. 2002). This may be consistent with the ability of Sox17 to promote thrombopoiesis and erythropoiesis and to impede lymphopoiesis (Figs. 2, 3).

\section{Discussion}

Our data suggest that SOX17 is a key determinant of fetal HSC identity and that ectopic expression of Sox17 in multipotent adult hematopoietic progenitors is sufficient to confer many properties of fetal HSCs. We showed previously that Sox 17 is highly restricted in its expression within the hematopoietic system to fetal and neonatal HSCs and that Sox17 expression is extinguished postnatally, as HSCs acquire an adult identity (Kim et al. 2007). Sox 17 is required for the maintenance of fetal and neonatal, but not adult, HSCs (Kim et al. 2007). In the current study, a more detailed analysis of Sox17 expression revealed that Sox17 expression declines with developmental time and lineage restriction (Fig. 1).

Ectopic Sox17 expression in adult bone marrow cells increased their capacity to give long-term multilineage reconstitution of irradiated mice, significantly increasing the levels at which myeloid cells, erythroid cells, and platelets were produced (Fig. 2). These effects were reminiscent of fetal liver HSCs, which have increased selfrenewal potential relative to adult bone marrow HSCs (Bowie et al. 2007), have increased reconstituting capacity in irradiated mice (Morrison et al. 1995; Harrison et al. 1997), and give rise predominantly to erythropoiesis and myelopoiesis in the fetal liver.

Fetal mice also have hematopoiesis in the spleen and form myeloid and megakaryocyte lineage cells that are phenotypically distinct from those formed in adult bone marrow. Consistent with this, recipients of Sox17-expressing bone 
marrow cells had larger spleens than control recipients, much higher levels of donor erythropoiesis and thrombopoiesis, and much lower levels of donor lymphoid cells in their spleens relative to control mice (Fig. 3). This did not reflect the existence of a neoplasm at this time point, as splenic architecture was normal throughout the first 16 wk after transplantation in most primary recipient mice and erythropoiesis was clearly visible in the spleen (data not shown). Recipients of Sox17-expressing cells appeared to have elevated levels of extramedullary hematopoiesis as well as myelopoiesis and thrombopoiesis that phenotypically resembled fetal liver hematopoiesis (Fig. $3 F, G)$. These results suggest that Sox17 expression is sufficient to cause adult bone marrow cells to undergo hematopoiesis that has features of fetal hematopoiesis.

The fetal liver contains a higher frequency of HSCs as compared with adult bone marrow (Morrison et al. 1995; Harrison et al. 1997). Recipients of Sox17-expressing bone marrow cells tended to have a lower frequency of $\mathrm{GFP}^{+}$ $\mathrm{CD} 150^{+} \mathrm{CD} 48^{-}$LSK cells (Fig. 4B), a highly purified population of HSCs (Kiel et al. 2005b), but they had a greatly expanded population of $\mathrm{GFP}^{+} \mathrm{CD} 48^{+} \mathrm{LSK}$ cells (Fig. 4C). CD48 ${ }^{+}$LSK cells from normal adult mice or CD $48^{+}$LSK cells infected by MSCV-GFP control virus gave low levels of transient multilineage reconstitution (Fig. 5B,C; Supplemental Fig. 3). In contrast, CD $48^{+}$LSK cells infected with MSCV-Sox17 gave long-term multilineage reconstitution, particularly in the myeloid, erythroid, and platelet lineages (Fig. 5B,C). These results suggest that ectopic Sox17 expression can confer fetal HSC characteristics upon multipotent adult hematopoietic progenitors.

Sox17 expression also induced fetal HSC markers in CD48 ${ }^{+}$LSK cells, including ESAM, Tie-2, Mac-1, VECadherin, and AA4.1 (Fig. 4D-H). However, these cells were not fully reprogrammed to a fetal HSC phenotype, as normal fetal liver HSCs do not express CD48 (Kim et al. 2006).

In our experiments, Sox17 was usually constitutively expressed from a retroviral promoter (Supplemental Fig. 1), rather than from native regulatory elements that allow Sox17 expression to be extinguished as cells differentiate (Kim et al. 2006). This enforced ectopic Sox17 expression in differentiating cells could have impaired the differentiation of lymphoid cells (Fig. 5). Consistent with this, Sox17-expressing cells generated lymphoid progeny (Fig. $2 \mathrm{E}-\mathrm{G})$, but often in smaller numbers than control cells, especially in secondary recipients (Fig. 5). Sox17 expression also eliminated the expression of genes required for lymphoid differentiation, including Rag1 and Rag2 (Fig. 7F). Therefore, the paucity of lymphopoiesis from Sox17expressing cells in some experiments did not necessarily reflect a lack of lymphoid potential.

Sox17-expression induced the expression of many genes that are preferentially expressed by HSCs, particularly fetal HSCs (Fig. 7; Supplemental Fig. 8), while reducing the expression of many genes that are preferentially expressed by restricted progenitors or differentiating cells (Fig. 7; Supplemental Fig. 8). Nonetheless, while Sox17 expression caused global changes in gene expres- sion within CD48 ${ }^{+}$LSK cells and HSCs that made these cells look and act more like fetal HSCs, the gene expression profile of Sox17-expressing CD48 ${ }^{+} \mathrm{LSK}$ cells or Sox17-transgenic HSCs was not identical to fetal HSCs (Fig. 7C; Supplemental Fig. 8). Importantly, retroviral or transgenic Sox17 expression in adult hematopoietic progenitors did not induce the expression of the endogenous Sox17 gene (data not shown). All of these results suggest that adult hematopoietic progenitors were not fully reprogrammed to a fetal HSC identity.

There are a number of potential explanations for the incomplete reprogramming by Sox 17 . One possibility is that other fetal HSC genes are required to fully reprogram adult hematopoietic progenitors to a fetal HSC identity. Another possibility is that the differences in gene expression and function between Sox 17 -expressing CD $48^{+} \mathrm{LSK}$ cells and fetal HSCs reflected the influence of the bone marrow microenvironment. It may not be possible for adult cells to fully adopt fetal HSC properties as long as they are present in the adult bone marrow environment. Unfortunately, it may not be technically possible to successfully transplant Sox 17-expressing CD $48^{+}$LSK cells into fetal liver, as very large numbers of these cells would have to be transplanted using trans-uterine injections in order to recover enough cells for analysis. Even if enough of the cells could be obtained, and they could be reliably injected into the liver, it is not clear that they would localize to appropriate niches or that they would have enough time in those microenvironments to be fully reprogrammed. Thus, in contrast to the reprogramming of mature cells to iPS cells, in which both reprogrammed and pluripotent cells can be studied in the same culture environment, the reprogrammed cells in our study could not be studied in the fetal environment. As a result, we do not know whether Sox17 is capable of fully, or only partially, reprogramming adult progenitors to a fetal HSC identity.

Sox17 is also expressed by visceral and definitive endoderm (Yasunaga et al. 2005), and by a subset of vascular endothelial cells. It regulates the formation and/or maintenance of these cell lineages during embryonic development (Hudson et al. 1997; Kanai-Azuma et al. 2002; Matsui et al. 2006; Niakan et al. 2010). In the current study, ectopic Sox17 expression in adult hematopoietic progenitors conferred fetal HSC characteristics rather than endodermal or endothelial identity. This suggests that the ability of Sox17 to specify a particular cell fate is contextdependent and that other transcriptional or epigenetic mechanisms in hematopoietic cells are likely to provide a context in which Sox17 is able to confer fetal HSC characteristics rather than endodermal identities.

Ectopic Sox17 expression in adult hematopoietic cells was not sufficient to transform these cells, as leukemias were not apparent in most primary recipient mice within 16 wk after reconstitution by MSCV-Sox17-infected cells (Fig. 7G). However, it appeared that ectopic expression of Sox17 contributed to the eventual transformation of adult cells, presumably in collaboration with secondary mutations, because secondary recipient mice rapidly succumbed to nonlymphoid leukemias (Fig. $7 \mathrm{H}$ ). These 
secondary recipient mice were anemic and their splenic architecture was completely effaced by leukemia cells, phenotypes not observed in healthy primary recipients within 16 wk of reconstitution. Thus, the multilineage reconstitution patterns observed in primary recipient mice did not appear to be influenced by the leukemias that eventually developed from Sox17-expressing cells. Instead, our data suggest that in addition to its ability to confer fetal HSC characteristics, Sox17 is likely a protooncogene that can collaborate with other mutations to cause leukemia. It will be interesting to determine whether Sox17 is induced in any adult leukemias observed in patients.

Our study demonstrates that ectopic Sox17 expression in multipotent adult hematopoietic progenitors confers fetal HSC characteristics, including increased self-renewal potential (Figs. 2G, 5C, 6C), increased reconstituting potential (Figs. 2, 5, 6), increased expression of fetal HSC markers (Fig. 4D-H), global changes in gene expression that resemble fetal HSCs (Fig. 7A-F), and changes in differentiation that resemble fetal hematopoiesis (Fig. 3). These results establish SOX17 as a key determinant of fetal HSC identify and demonstrate a remarkable capacity of adult hematopoietic progenitors to acquire more immature characteristics under the influence of a single transcription factor.

\section{Materials and methods}

Mice

C57BL/Ka-Thy-1.1 (CD45.2) and C57BL/Ka-Thy-1.2 (CD45.1) mice were housed in the Unit for Laboratory Animal Medicine at the University of Michigan. All experiments were performed in accordance with protocols approved by the University Committee on the Use and Care of Animals. (tetO) ${ }_{7} C M V S o x 17-I R E S$ NucEGFP mice (Park et al. 2006) were kindly provided by Dr. Jeffrey Whitsett at Cincinnati Children's Hospital Medical Center. B6.CgGt(ROSA)26Sor ${ }^{\text {tm1 } 1\left(r t T A^{*} M 2\right) J a e} / \mathrm{J}$ mice (Hochedlinger et al. 2005) and C57BL/6-Tg(UBC-GFP)30Scha// mice (UBC-GFP mice) were purchased from Jackson Laboratory. (tetO) ${ }_{7}$ CMVSox17-IRES-NucEGFP mice were crossed with B6.Cg-Gt(ROSA)26Sor ${ }^{\operatorname{tm} 1\left(r t T A^{*} M 2\right) J a e} / \mathrm{J}$ mice to generate doxycycline-inducible compound transgenic mice. Ubiquitous Sox17 transgene expression was induced by administering $2 \mathrm{mg} / \mathrm{mL}$ doxycycline in the drinking water of 8-wk-old compound transgenic mice for 5-7 d.

\section{Antibodies and flow cytometry}

All primary antibodies used for flow cytometry were purchased from eBiosciences, Biolegend, or BD Biosciences unless otherwise indicated. Alexa Fluor 700 and PE-Texas Red-conjugated streptavidin was purchased from Invitrogen, and FITC-conjugated streptavidin was purchased from Jackson ImmunoResearch Laboratories. All flow cytometry was performed on a customized FACSAria II three-laser, 10-color flow cytometer (Becton-Dickinson).

To isolate HSCs and hematopoietic progenitors from adult mouse bone marrow, bone marrow cells were obtained from both hindlimbs, pelvis, and vertebrae by crushing the bones with a mortar and pestle, then resuspending in ice-cold staining medium $(1 \times$ Hank's buffered salt solution without calcium or magnesium, supplemented with $2 \%$ heat-inactivated calf serum
[Invitrogen]) and filtered through $40-\mu \mathrm{m}$ nylon mesh (Sefar). Unfractionated bone marrow cells were first enriched by staining with APC-Efluor780-conjugated anti-c-kit antibody (2B8), followed by incubation with anti-APC magnetic beads and magnetic selection using autoMACS (Miltenyi). The c-kit-enriched cells were then stained with PE-conjugated monoclonal antibodies against lineage markers (CD41, ebioMWReg30; CD2, RM2-5; CD3e, 145-2c11; CD5, 53-7.3; CD8a, 53-6.7; B220, RA36B2; Gr-1, RB6-8C5; Ter-119 and CD127, A7R34), PE-Cy5conjugated anti-CD150 (TC15-12F12.2, Biolegend), PE-Cy7-conjugated anti-Sca-1 (E13-161.7), Alexa Fluor 700-conjugated antiCD16/32 (Fc $\gamma R$, 93), biotin-conjugated anti-CD105 (MJ7/18), and APC-conjugated anti-CD48 (HM48-1). CD105 staining was developed with FITC-conjugated streptavidin. HSCs and hematopoietic progenitor cells were sorted as the following phenotypes: HSCs (Lineage ${ }^{-}$c-kit ${ }^{+}$Sca- $1^{+} \mathrm{CD} 150^{+} \mathrm{CD} 48^{-}$), MPPs (Lineage ${ }^{-}$Sca$1^{+} \mathrm{c}-\mathrm{kit}^{+} \mathrm{CD} 150^{-} \mathrm{CD} 48^{-}$) (Kiel et al. 2005b), CD48 ${ }^{+} \mathrm{LSK}$ cells $\left(\right.$ Lineage $^{-}$Sca- ${ }^{+}{ }^{+}$-kit ${ }^{+} \mathrm{CD} 48^{+}$), GMPs (Lineage ${ }^{-}$c-kit ${ }^{+}$Sca- ${ }^{-}$CD16/ $32^{+}$), and megakaryocyte/erythroid progenitors (Pre-MegE; Lineage $^{-}$c-kit $^{+}$Sca- ${ }^{-} \mathrm{CD} 16 / 32^{-} \mathrm{CD} 150^{+} \mathrm{CD}^{-}{ }^{-}$) (Pronk et al. 2007). Cells were resuspended in $2 \mu \mathrm{g} / \mathrm{mL}$ DAPI to discriminate live from dead cells during flow cytometry.

To assess the differentiation of $\mathrm{GFP}^{+}$donor-derived cells in primary and secondary recipient mice, single-cell suspensions of flushed bone marrow cells, splenocytes, and/or thymocytes were prepared as previously described (Yilmaz et al. 2006). Unfractionated cells were stained with antibodies specific for myeloid cells (Mac-1-APC [M1/70], Gr-1-PE/Cy7 [RB6-8C5]) megakaryocyte lineage cells (CD41-PE [eBioMWReg30] and CD42d [1C2]), erythroid cells ([Ter119-APC and CD71-PE [R17217]), B cells (B220-PE/Cy5 [RA3-6B2], CD43-PE [S7], and sIgM-APC [11/41]), or $\mathrm{T}$ cells (CD3e-APC [145-2c11], CD4-PE/Cy7 [GK1.5], and CD8-PE [53-6.7]), together with APC-Efluor780-conjugated anti-CD45.1 (A20) and Alexa Fluor 700-conjugated anti-CD45.2 (104) to distinguish donor from recipient cells. To analyze the frequency of HSCs and LSK cells in the GFP' fraction of recipient bone marrow and spleen cells, unfractionated cells were stained with PE-conjugated antibodies against lineage markers as described above, and antibodies against CD150 (TC15-12F12.2; PECy5), CD48 (HM48-1; PE-Cy7), c-kit (2B8; PE-Alexa Fluor 610), and Sca-1 (E13-161.7; APC-Cy7). APC-conjugated anti-CD93 (AA4.1), APC-conjugated anti-ESAM (1G8), or Alexa Fluor 647conjugated anti-CD144 (eBioBV13) were sometimes included to assess the expression of these markers on Sox17-expressing cells.

Viral infection of whole bone marrow and hematopoietic progenitors

The generation of MSCV-Sox17 and MSCV-Sox17his retroviruses is described in the Supplemental Material. For adult whole bone marrow cell infection, three to five donor mice (CD45.1) were treated with a single injection of $150 \mathrm{mg} / \mathrm{kg} 5$-fluorouracil, and bone marrow cells from both hindlimbs and pelvis were harvested on day 4 by flushing. Pooled bone marrow cells were first treated with ammonium-chloride potassium red cell lysis buffer to enrich for mononuclear cells (Kiel et al. 2005b), then resuspended in prestimulation cytokine cocktail $(1 \times$ DMEM supplemented with $15 \%$ fetal bovine serum [FBS], $1 \%$ penicillin/ streptomycin [Pen/strep], $100 \mathrm{ng} / \mathrm{mL}$ stem cell factor [SCF], 10 $\mathrm{ng} / \mathrm{mL}$ interleukin-3 [IL-3], $10 \mathrm{ng} / \mathrm{mL}$ interleukin-6 [IL-6], $50 \mu \mathrm{M}$ 2-mercaptoethanol [2-ME]) at a concentration of $5 \times 10^{6}$ cells per milliliter, and incubated in a $37^{\circ} \mathrm{C}$ incubator with $6 \% \mathrm{CO}_{2}$ for $\sim 24 \mathrm{~h}$. Two spin infections were performed at 24 and $36 \mathrm{~h}$ after culture initiation by adding retrovirus supernatant $(\mathrm{MOI}=2)$ and $4 \mathrm{ng} / \mathrm{mL}$ polybrene to the cell suspension and spinning at $1300 \mathrm{~g}$ 
for $90 \mathrm{~min}$ at room temperature. Cells were harvested $5 \mathrm{~h}$ after the second spin, counted, and transplanted into irradiated mice.

For infection of purified adult hematopoietic progenitor cells, 500 or 2000 HSCs, MPPs, CD48 ${ }^{+}$LSK cells, GMPs, or Pre-MegEs were double-sorted from untreated wild-type adult donor mice and deposited into a 96-well round-bottom plate containing 100 $\mu \mathrm{L}$ of prestimulation cytokine cocktail. The base medium was $1 \times \alpha$-MEM plus $1 \%$ FBS plus $1 \%$ Penn/strep supplemented with cytokines specific for HSCs $(50 \mathrm{ng} / \mathrm{mL}$ SCF and $50 \mathrm{ng} / \mathrm{mL}$ thrombopoietin [TPO]), MPPs (50 ng/mL SCF, $50 \mathrm{ng} / \mathrm{mL}$ Flt3ligand, $50 \mathrm{ng} / \mathrm{mL}$ TPO, and $10 \mathrm{ng} / \mathrm{mL}$ IL-3), CD $48^{+} \mathrm{LSK}$ cells or GMPs (100 ng/mL SCF, $10 \mathrm{ng} / \mathrm{mL} \mathrm{IL-3,} \mathrm{and} 10 \mathrm{ng} / \mathrm{mL} \mathrm{IL}-6)$, or pre-MegEs $(100 \mathrm{ng} / \mathrm{mL}$ SCF, $10 \mathrm{ng} / \mathrm{mL}$ IL-3, $10 \mathrm{ng} / \mathrm{mL}$ IL-6, and $2 \mathrm{U} / \mathrm{mL}$ erythropoietin [EPO]). Viral supernatant was added at 0 and $12 \mathrm{~h}$ (for CD $48^{+}$LSK cells, GMPs, and Pre-MegEs) or 24 and $36 \mathrm{~h}$ (for HSCs and MPPs) after culture initiation at MOI $=200$. Cells from each well were harvested $12 \mathrm{~h}$ after the second round of viral infection and transplanted into irradiated recipient mice along with 200,000 recipient cells for radioprotection. Viral infection efficiency was determined by analyzing cells infected in parallel at $48 \mathrm{~h}$ after the second round of infection using flow cytometry.

Detailed methods for long-term reconstitution assays, histological analysis, microarray analysis, quantitative RT-PCR, and Western blotting can be found in the Supplemental Material. The raw data for the microarray analysis may be obtained from Gene Expression Omnibus (GSE30446).

\section{Acknowledgments}

Thanks to Tina Levanthal for the initial construction of the MSCV-Sox17 and MSCV-Sox17his retroviral vectors. Thanks to Dr. Jeffery Whitsett at Cincinnati Children's Hospital for providing the (tetO)7CMVSox17-IRES-NucEGFP transgenic mice. Thanks to David Adams, Martin White, and Ann Marie Deslaurier of the University of Michigan Flow Cytometry Core Facility. Thanks to the histology cores at the University of Michigan Microscopy and Image Analysis Laboratory and the University of Michigan Comprehensive Cancer Center for histology service. Thanks to Craig Johnson, Joseph Washburn, and Melih Acar for technical assistances with microarray analyses. This work was supported by the National Institute on Aging (2 R37 AG024945) and the Howard Hughes Medical Institute. Flow cytometry was supported in part by the University of Michigan Comprehensive Cancer Center NIH CA46592, and antibody generation was supported by the University of Michigan Multipurpose Arthritis Center NIH AR20557. S.H. performed all experiments and participated in the design and interpretation of all experiments. I.K. generated the Sox17-GFP knock-in mice and performed preliminary experiments. M.S.L. analyzed mouse pathology with help from S.H. S.J.M. participated in the design and interpretation of all experiments and wrote the manuscript with S.H.

\section{References}

Akashi K, Traver D, Miyamoto T, Weissman IL. 2000. A clonogenic common myeloid progenitor that gives rise to all myeloid lineages. Nature 404: 193-197.

Arai F, Hirao A, Ohmura M, Sato H, Matsuoka S, Takubo K, Ito K, Koh GY, Suda T. 2004. Tie2/angiopoietin-1 signaling regulates hematopoietic stem cell quiescence in the bone marrow niche. Cell 118: 149-161.

Bowie MB, Kent DG, Dykstra B, McKnight KD, McCaffrey L, Hoodless PA, Eaves CJ. 2007. Identification of a new intrinsically timed developmental checkpoint that reprograms key hematopoietic stem cell properties. Proc Natl Acad Sci 104: $5878-5882$.
Buonamici S, Li D, Chi Y, Zhao R, Wang X, Brace L, Ni H, Saunthararajah Y, Nucifora G. 2004. EVI1 induces myelodysplastic syndrome in mice. J Clin Invest 114: 713-719.

Cumano A, Dieterlen-Lievre F, Godin I. 1996. Lymphoid potential, probed before circulation in mouse, is restricted to caudal intraembryonic splanchnopleura. Cell 86: 907-916.

Cumano A, Ferraz JC, Klaine M, Di Santo JP, Godin I. 2001. Intraembryonic, but not yolk sac hematopoietic precursors, isolated before circulation, provide long-term multilineage reconstitution. Immunity 15: 477-485.

Ficara F, Murphy MJ, Lin M, Cleary ML. 2008. Pbxl regulates self-renewal of long-term hematopoietic stem cells by maintaining their quiescence. Cell Stem Cell 2: 484-496.

Gekas C, Dieterlen-Lievre F, Orkin SH, Mikkola HK. 2005. The placenta is a niche for hematopoietic stem cells. Dev Cell 8: 365-375.

Goyama S, Yamamoto G, Shimabe M, Sato T, Ichikawa M, Ogawa S, Chiba S, Kurokawa M. 2008. Evi-1 is a critical regulator for hematopoietic stem cells and transformed leukemic cells. Cell Stem Cell 3: 207-220.

Harrison DE, Zhong RK, Jordan CT, Lemischka IR, Astle CM. 1997. Relative to adult marrow, fetal liver repopulates nearly five times more effectively long-term than short-term. Exp Hematol 25: 293-297.

Hochedlinger K, Yamada Y, Beard C, Jaenisch R. 2005. Ectopic expression of Oct-4 blocks progenitor-cell differentiation and causes dysplasia in epithelial tissues. Cell 121: 465-477.

Hock H, Hamblen MJ, Rooke HM, Schindler JW, Saleque S, Fujiwara Y, Orkin SH. 2004a. Gfi-1 restricts proliferation and preserves functional integrity of haematopoietic stem cells. Nature 431: 1002-1007.

Hock H, Meade E, Medeiros S, Schindler JW, Valk PJ, Fujiwara Y, Orkin SH. 2004b. Tel/Etv6 is an essential and selective regulator of adult hematopoietic stem cell survival. Genes Dev 18: 2336-2341.

Hsu HC, Ema H, Osawa M, Nakamura Y, Suda T, Nakauchi H. 2000. Hematopoietic stem cells express Tie-2 receptor in the murine fetal liver. Blood 96: 3757-3762.

Hudson C, Clements D, Friday RV, Stott D, Woodland HR. 1997. Xsox $17 \alpha$ and $-\beta$ mediate endoderm formation in Xenopus. Cell 91: 397-405.

Ikuta K, Kina T, Macneil I, Uchida N, Peault B, Chien YH, Weissman IL. 1990. A developmental switch in thymic lymphocyte maturation potential occurs at the level of hematopoietic stem cells. Cell 62: 863-874.

Ivanova NB, Dimos JT, Schaniel C, Hackney JA, Moore KA, Lemischka IR. 2002. A stem cell molecular signature. Science 298: 601-604.

Jordan CT, Lemischka IR. 1990. Clonal and systemic analysis of long-term hematopoiesis in the mouse. Genes Dev 4: 220-232.

Jordan CT, McKearn JP, Lemischka IR. 1990. Cellular and developmental properties of fetal hematopoietic stem cells. Cell 61: 953-963.

Kanai-Azuma M, Kanai Y, Gad JM, Tajima Y, Taya C, Kurohmaru M, Sanai Y, Yonekawa H, Yazaki K, Tam PP, et al. 2002. Depletion of definitive gut endoderm in Sox17-null mutant mice. Development 129: 2367-2379.

Kantor AB, Stall AM, Adams S, Herzenberg LA, Herzenberg LA. 1992. Differential development of progenitor activity for three B-cell lineages. Proc Natl Acad Sci 89: 3320-3324.

Kiel MJ, Iwashita T, Yilmaz OH, Morrison SJ. 2005a. Spatial differences in hematopoiesis but not in stem cells indicate a lack of regional patterning in definitive hematopoietic stem cells. Dev Biol 283: 29-39.

Kiel MJ, Yilmaz OH, Iwashita T, Terhorst C, Morrison SJ. 2005b. SLAM family receptors distinguish hematopoietic stem and 
progenitor cells and reveal endothelial niches for stem cells. Cell 121: 1109-1121.

Kiel MJ, Yilmaz OH, Morrison SJ. 2008. CD150- cells are transiently reconstituting multipotent progenitors with little or no stem cell activity. Blood 111: 4413-4414.

Kim I, Yilmaz OH, Morrison SJ. 2005. CD144 (VE-cadherin) is transiently expressed by fetal liver hematopoietic stem cells. Blood 106: 903-905.

Kim I, He S, Yilmaz OH, Kiel MJ, Morrison SJ. 2006. Enhanced purification of fetal liver hematopoietic stem cells using SLAM family receptors. Blood 108: 737-744.

Kim I, Saunders TL, Morrison SJ. 2007. Sox17 dependence distinguishes the transcriptional regulation of fetal from adult hematopoietic stem cells. Cell 130: 470-483.

Kogan SC, Ward JM, Anver MR, Berman JJ, Brayton C, Cardiff RD, Carter JS, deCoronado S, Downing JR, Fredrickson TN, et al. 2002. Bethesda proposals for classification of nonlymphoid hematopoietic neoplasms in mice. Blood 100: 238-245.

Krosl J, Baban S, Krosl G, Rozenfeld S, Largman C, Sauvageau G. 1998. Cellular proliferation and transformation induced by HOXB4 and HOXB3 proteins involves cooperation with PBX1. Oncogene 16: 3403-3412.

Lee LK, Ueno M, Van Handel B, Mikkola HK. 2010. Placenta as a newly identified source of hematopoietic stem cells. Curr Opin Hematol 17: 313-318.

Matsui T, Kanai-Azuma M, Hara K, Matoba S, Hiramatsu R, Kawakami H, Kurohmaru M, Koopman P, Kanai Y. 2006. Redundant roles of Sox17 and Sox18 in postnatal angiogenesis in mice. I Cell Sci 119: 3513-3526.

Medvinsky A, Dzierzak E. 1996. Definitive hematopoiesis is autonomously initiated by the AGM region. Cell 86: 897-906.

Mikkola HK, Orkin SH. 2006. The journey of developing hematopoietic stem cells. Development 133: 3733-3744.

Min IM, Pietramaggiori G, Kim FS, Passegue E, Stevenson KE, Wagers AJ. 2008. The transcription factor EGR1 controls both the proliferation and localization of hematopoietic stem cells. Cell Stem Cell 2: 380-391.

Mombaerts P, Iacomini J, Johnson RS, Herrup K, Tonegawa S, Papaioannou VE. 1992. RAG-1-deficient mice have no mature B and T lymphocytes. Cell 68: 869-877.

Morrison SJ, Hemmati HD, Wandycz AM, Weissman IL. 1995. The purification and characterization of fetal liver hematopoietic stem cells. Proc Natl Acad Sci 92: 10302-10306.

Niakan KK, Ji H, Maehr R, Vokes SA, Rodolfa KT, Sherwood RI, Yamaki M, Dimos JT, Chen AE, Melton DA, et al. 2010. Sox17 promotes differentiation in mouse embryonic stem cells by directly regulating extraembryonic gene expression and indirectly antagonizing self-renewal. Genes Dev 24: 312 326.

Orkin SH, Zon LI. 2008. Hematopoiesis: an evolving paradigm for stem cell biology. Cell 132: 631-644.

Park IK, Qian D, Kiel M, Becker MW, Pihalja M, Weissman IL, Morrison SJ, Clarke MF. 2003. Bmi-1 is required for maintenance of adult self-renewing haematopoietic stem cells. Nature 423: 302-305.

Park KS, Wells JM, Zorn AM, Wert SE, Whitsett JA. 2006. Sox17 influences the differentiation of respiratory epithelial cells. Dev Biol 294: 192-202.

Pear WS, Miller JP, Xu L, Pui JC, Soffer B, Quackenbush RC, Pendergast AM, Bronson R, Aster JC, Scott ML, et al. 1998. Efficient and rapid induction of a chronic myelogenous leukemia-like myeloproliferative disease in mice receiving P210 bcr/abl-transduced bone marrow. Blood 92: 3780-3792.

Phillips RL, Ernst RE, Brunk B, Ivanova N, Mahan MA, Deanehan JK, Moore KA, Overton GC, Lemischka IR. 2000. The genetic program of hematopoietic stem cells. Science 288: 16351640.

Pronk CJH, Rossi DJ, Mansson R, Attema JL, Norddahl GL, Chan CKF, Sigvardsson M, Weissman IL, Bryder D. 2007. Elucidation of the phenotypic, functional, and molecular topography of a myeloerythroid progenitor cell hierarchy. Cell Stem Cell 1: 428-442.

Puri MC, Bernstein A. 2003. Requirement for the TIE family of receptor tyrosine kinases in adult but not fetal hematopoiesis. Proc Natl Acad Sci 100: 12753-12758.

Rodrigues NP, Janzen V, Forkert R, Dombkowski DM, Boyd AS, Orkin SH, Enver T, Vyas P, Scadden DT. 2005. Haploinsufficiency of GATA-2 perturbs adult hematopoietic stem-cell homeostasis. Blood 106: 477-484.

Samokhvalov IM, Samokhvalova NI, Nishikawa S. 2007. Cell tracing shows the contribution of the yolk sac to adult haematopoiesis. Nature 446: 1056-1061.

Sanchez MJ, Holmes A, Miles C, Dzierzak E. 1996. Characterization of the first definitive hematopoietic stem cells in the AGM and liver of the mouse embryo. Immunity 5: 513-525.

Shinkai Y, Rathbun G, Lam KP, Oltz EM, Stewart V, Mendelsohn M, Charron J, Datta M, Young F, Stall AM, et al. 1992. RAG-2deficient mice lack mature lymphocytes owing to inability to initiate V(D)J rearrangement. Cell 68: 855-867.

Tsai F-Y, Keller G, Kuo FC, Weiss M, Chen J, Rosenblatt M, Alt FW, Orkin SH. 1994. An early haematopoietic defect in mice lacking the transcription factor GATA-2. Nature 371: 221226.

Van Parijs L, Refaeli Y, Lord JD, Nelson BH, Abbas AK, Baltimore D. 1999. Uncoupling IL-2 signals that regulate T cell proliferation, survival, and Fas-mediated activation-induced cell death. Immunity 11: 281-288.

Weissman I, Papaioannou V, Gardner R. 1978. Fetal hematopoietic origins of the adult hematolymphoid system. In Cold Spring Harbor conferences on cell proliferation Vol 5: Differentiation of normal and neoplastic hematopoietic cells (ed. B Clarkson, et al.), pp. 33-47. Cold Spring Harbor Laboratory, Cold Spring Harbor, NY.

Yano M, Iwama A, Nishio H, Suda J, Takada G, Suda T. 1997. Expression and function of murine receptor tyrosine kinases, TIE and TEK, in hematopoietic stem cells. Blood 89: 43174326.

Yasunaga M, Tada S, Torikai-Nishikawa S, Nakano Y, Okada M, Jakt LM, Nishikawa S, Chiba T, Era T. 2005. Induction and monitoring of definitive and visceral endoderm differentiation of mouse ES cells. Nat Biotechnol 23: 1542-1550.

Yilmaz OH, Valdez R, Theisen BK, Guo W, Ferguson DO, Wu H, Morrison SJ. 2006. Pten dependence distinguishes haematopoietic stem cells from leukaemia-initiating cells. Nature 441: 475-482.

Yoder MC, Hiatt K, Mukherjee P. 1997. In vivo repopulating hematopoietic stem cells are present in the murine yolk sac at day 9.0 postcoitus. Proc Natl Acad Sci 94: 6776-6780.

Yokota T, Oritani K, Butz S, Kokame K, Kincade PW, Miyata T, Vestweber D, Kanakura Y. 2009. The endothelial antigen ESAM marks primitive hematopoietic progenitors throughout life in mice. Blood 113: 2914-2923. 


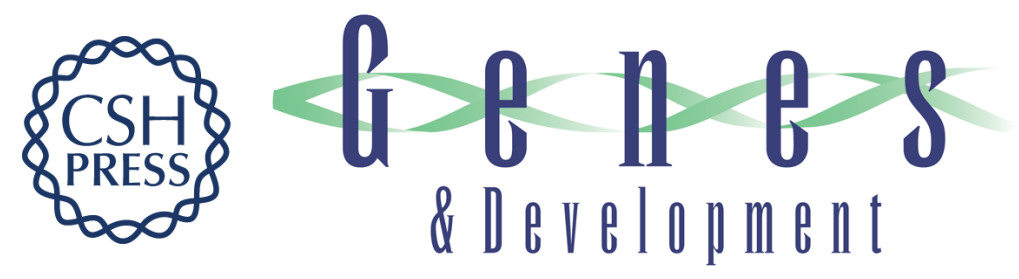

\section{Sox17 expression confers self-renewal potential and fetal stem cell characteristics upon adult hematopoietic progenitors}

Shenghui He, Injune Kim, Megan S. Lim, et al.

Genes Dev. 2011, 25:

Access the most recent version at doi:10.1101/gad.2052911

\section{Supplemental http://genesdev.cshlp.org/content/suppl/2011/08/09/25.15.1613.DC1 Material}

Related Content Return to youth with Sox17

Akanksha Chhabra and Hanna K.A. Mikkola

Genes Dev. August , 2011 25: 1557-1562

References This article cites 55 articles, 21 of which can be accessed free at: http://genesdev.cshlp.org/content/25/15/1613.full.html\#ref-list-1

Articles cited in:

http://genesdev.cshlp.org/content/25/15/1613.full.html\#related-urls

\section{License}

Email Alerting Receive free email alerts when new articles cite this article - sign up in the box at the top Service right corner of the article or click here.

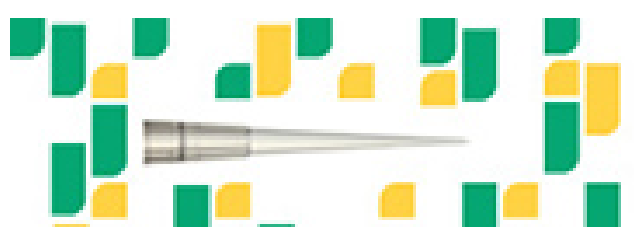

Focused on your science. 